\title{
XANES and Mg isotopic analyses of spinels in Ca-Al-rich inclusions: Evidence for formation under oxidizing conditions
}

\author{
J. M. PAQUE ${ }^{1 *}$, S. R. SUTTON ${ }^{2}$, S. B. SIMON ${ }^{2}$, J. R. BECKETT ${ }^{1}$, D. S. BURNETT ${ }^{1}$, \\ L. GROSSMAN ${ }^{2,3}$, H. YURIMOTO ${ }^{4}$, S. ITOH $^{4}$, and H. C. CONNOLLY JR. ${ }^{5-8}$ \\ ${ }^{1}$ Division of Geological and Planetary Sciences, Caltech, Pasadena, California 91125, USA \\ ${ }^{2}$ Department of Geophysical Sciences, The University of Chicago, Chicago, Illinois 60637, USA \\ ${ }^{3}$ Enrico Fermi Institute, The University of Chicago, $5640 \mathrm{~S}$ Ellis Ave., Chicago, Illinois 60637, USA \\ ${ }^{4}$ Department of Natural History Science, Hokkaido University, Sapporo, Hokkaido, Japan \\ ${ }^{5}$ Department of Physical Sciences, Kingsborough Community College of the City University of New York, \\ 2001 Oriental Boulevard, Brooklyn, New York 11235, USA \\ ${ }^{6}$ Department of Earth and Environmental Sciences, The Graduate Center of the City University of New York, \\ New York, New York 10016, USA \\ ${ }^{7}$ Department of Earth and Planetary Sciences, American Museum of Natural History, New York, New York 10024, USA \\ ${ }^{8}$ Lunar and Planetary Laboratory, University of Arizona, Tucson, Arizona 85721, USA \\ *Corresponding author. E-mail: julie@paque.com
}

(Received 11 March 2013; revision accepted 12 September 2013)

\begin{abstract}
Ti valence measurements in $\mathrm{MgAl}_{2} \mathrm{O}_{4}$ spinel from calcium-aluminum-rich inclusions (CAIs) by X-ray absorption near-edge structure (XANES) spectroscopy show that many spinels have predominantly tetravalent $\mathrm{Ti}$, regardless of host phases. The average spinel in Allende type B1 inclusion TS34 has $87 \% \mathrm{Ti}^{+4}$. Most spinels in fluffy type A (FTA) inclusions also have high Ti valence. In contrast, the rims of some spinels in TS34 and spinel grain cores in two Vigarano type B inclusions have larger amounts of trivalent titanium. Spinels from TS34 have approximately equal amounts of divalent and trivalent vanadium. Based on experiments conducted on CAI-like compositions over a range of redox conditions, both clinopyroxene and spinel should be $\mathrm{Ti}^{+3}$-rich if they equilibrated with CAI liquids under near-solar oxygen fugacities. In igneous inclusions, the seeming paradox of high-valence spinels coexisting with low-valence clinopyroxene can be explained either by transient oxidizing conditions accompanying low-pressure evaporation or by equilibration of spinel with relict $\mathrm{Ti}^{+4}$-rich phases (e.g., perovskite) prior to or during melting. Ion probe analyses of large spinel grains in TS34 show that they are enriched in heavy $\mathrm{Mg}$, with an average $\Delta^{25} \mathrm{Mg}$ of $4.25 \pm 0.028 \%$, consistent with formation of the spinel from an evaporating liquid. $\Delta^{25} \mathrm{Mg}$ shows small, but significant, variation, both within individual spinels and between spinel and adjacent melilite hosts. The $\Delta^{25} \mathrm{Mg}$ data are most simply explained by the low-pressure evaporation model, but this model has difficulty explaining the high $\mathrm{Ti}^{+4}$ concentrations in spinel.
\end{abstract}

\section{INTRODUCTION}

The redox conditions experienced by natural materials exert a major control on phase assemblages and phase compositions, whether they are liquids undergoing crystallization or evaporation, condensates reacting in a gas, or rocks undergoing partial melting or metasomatism. By inverting the observed mineral and rock bulk compositions as we now see them, it is often possible to constrain the nature of events that produced them. This is particularly important in the study of meteorites, for which a field context is largely lost, even in the largest of samples. Calcium-aluminum-rich inclusions (CAIs), which are small objects (generally $<1 \mathrm{~cm}^{3}$ ) included in certain meteorites, have no field context for their formation at all. Yet, CAIs and related 
objects are crucial for determining physicochemical environments in the early solar system. They are the oldest known objects formed in the solar system (e.g., Amelin et al. 2002; McKeegan and Davis 2005), and their bulk compositions are similar to those calculated for solid phase assemblages predicted to condense from a gas of solar composition (e.g., Yoneda and Grossman 1995; Ebel 2006).

It has long been recognized (e.g., Dowty and Clark 1973; Grossman 1975; Simon et al. 1991, 2007) that, in the Al-, Ti-rich variety of clinopyroxene in CAIs (termed "fassaite"), large proportions of the $\mathrm{Ti}$ are trivalent, indicating formation under reducing conditions. Based on experimental calibration of $\mathrm{Ti}^{+3} /$ $\mathrm{Ti}^{+4}$ in fassaite against oxygen fugacity, natural fassaite-bearing assemblages were found by Grossman et al. (2008a) to record equilibration at about one $\log$ unit below the $f \mathrm{O}_{2}$ of a solar gas, referenced to $1509 \mathrm{~K}$. Given the overall uncertainties, the $\mathrm{Ti}^{+3} / \mathrm{Ti}^{+4}$ of fassaite is, however, compatible with equilibration with a gas of solar composition at high temperature. In this paper, we refer to oxygen fugacities in log units relative to the $\mathrm{Fe}-\mathrm{FeO}$ (IW) buffer and, in these terms, the oxygen fugacity of a gas of solar composition, set by the relative abundances of $\mathrm{C}, \mathrm{O}$, and $\mathrm{H}$, is about IW-6.8 (e.g., $6.8 \mathrm{log}$ units below the iron-wüstite buffer) for the temperature range of $1500-1800 \mathrm{~K}$.

The concentrations of $\mathrm{Ti}$ in fassaite are often sufficiently high that $\mathrm{Ti}^{+3} / \mathrm{Ti}^{+4}$ ratios can be determined through stoichiometry (e.g., Simon et al. 1991). They can also be measured directly, even at low concentrations such as those found in spinel, by X-ray absorption near-edge structure spectroscopy (XANES; Waychunas 1987; Farges et al. 1997). XANES is based on that portion of an X-ray absorption spectrum within about $40 \mathrm{eV}$ of the main absorption edge jump. Intensities and energies of the XANES spectral features provide information on the valence and coordination environment of the element of interest.

Spinel is on the liquidus for many CAI-like bulk compositions (Stolper 1982; Paque and Stolper 1984) and, consequently, this phase may record igneous events or environments that predate crystallization of melilite and fassaite and, perhaps, even the formation of the host CAIs. As with clinopyroxene, the valence states of multivalent cations in spinel may provide useful indicators of oxygen fugacity, but these elements are generally present in minor to trace concentrations in unaltered spinel, so calculations based on electron microprobe analyses and the stoichiometry cannot be used to infer their valence states. Moreover, at least in Allende CAIs, there is clear evidence of preterrestrial secondary alteration, which led to the introduction of $\mathrm{Fe}$ into some spinels (Paque et al. 2007) and possible resetting of the valence distribution for other elements. In this study, we use XANES to determine $\mathrm{Ti}$ and $\mathrm{V}$ valences in spinel from well-characterized CAIs, both in the somewhat altered inclusions from the Allende CV3 chondrite and in the much more pristine inclusions from the reduced CV3 chondrites Efremovka and Vigarano (Sylvester et al. 1993; Paque et al. 2007; Simon et al. 2007). We also analyzed synthetic spinel and clinopyroxene crystallized from CAI-like liquids under a range of known oxygen fugacities for comparison with the natural samples. In addition, we used secondary ion mass spectrometry (SIMS) to determine the $\mathrm{Al}$ and $\mathrm{Mg}$ isotopic compositions of natural spinel to look for a correlation between $\mathrm{Mg}$ isotopic variations and $\mathrm{Ti}$ valences as revealed through XANES. Isotopic compositions were also determined in host melilite adjacent to spinel. Paque et al. (2010) and Simon et al. (2010) describe preliminary results of the work presented here.

\section{ANALYTICAL AND EXPERIMENTAL METHODS}

\section{Electron Microbeam}

A JEOL JSM-5800LV scanning electron microscope (SEM) equipped with an Oxford/Link ISIS-300 energy dispersive X-ray analysis system (The University of Chicago) and a Zeiss 1550 VP SEM equipped with an Oxford INCA Energy 300 X-ray energy-dispersive spectrometer system (Caltech) were used to determine the basic petrographic characteristics of the inclusions and to select spinel grains for more detailed analysis. Quantitative wavelength-dispersive analyses at the University of Chicago were obtained with a Cameca SX-50 electron microprobe operated at $15 \mathrm{kV}$ and a beam current of $25 \mathrm{nA}$ using counting times of 10-30 s each on peak and background for each element in an analysis. Pure oxide, synthetic glass, and natural mineral standards were used. Electron probe (EMP) data were reduced via the modified ZAF correction procedure PAP (Pouchou and Pichoir 1984). To calculate the $\mathrm{Ti}^{+3} / \mathrm{Ti}^{\text {tot }}$ ratio of clinopyroxene, where $\mathrm{Ti}^{\text {tot }}$ is the sum of $\mathrm{Ti}^{+3}$ and $\mathrm{Ti}^{+4}$, from an electron probe analysis, we assumed a stoichiometric pyroxene formula unit consisting of exactly four cations per six oxygens. We also assumed that there are exactly two tetrahedral cations and one calcium cation per 6 oxygen anions (Beckett 1986). This procedure is restricted to analyses with total $\mathrm{Ti}$ calculated as $\mathrm{TiO}_{2}\left(\mathrm{TiO}_{2}{ }^{*}\right)$ greater than approximately $4 \mathrm{wt} \%$ due to the relatively large analytical uncertainties (approaching 20\%; Simon et al. 1991) for Ti in Ti-poor pyroxene. Microprobe analyses of spinel carried out at Caltech followed procedures outlined in Paque et al. (2007). 


\section{XANES Measurements}

$\mathrm{Ti}$ and V K-edge XANES spectra were measured using the undulator-based microprobe at Sector 13 (GeoSoilEnviroCARS) at the Advanced Photon Source, Argonne National Laboratory (Sutton and Rivers 1999). X-ray microprobe techniques are described in detail elsewhere (e.g., Smith and Rivers 1995; Sutton et al. 2002). A Si (111) liquid nitrogen-cooled, doublecrystal, scannable monochromator was used. The instrumental energy resolution $(0.8 \mathrm{eV})$ was comparable to the natural $\mathrm{Ti}$ and $\mathrm{V} K_{\alpha}$ line widths (approximately $1 \mathrm{eV}$; Krause and Oliver 1979), so that the overall energy resolution of the $\mathrm{Ti}$ and $\mathrm{V} \mathrm{K}$ XANES spectra was about $1.3 \mathrm{eV}$.

Kirkpatrick-Baez (KB; Kirkpatrick and Baez 1948) microfocusing mirrors (Eng et al. 1998) were used to produce X-ray microbeams. The KB system consists of two mirrors (100 mm length), one in the horizontal plane and one in the vertical plane, which collected approximately $300 \mu \mathrm{m}$ of X-ray beam in both directions and produce a focal spot of approximately $2 \mu \mathrm{m}$ in both directions. The mirrors were constructed from highly polished, single-crystal silicon coated with several hundred $\AA$ of $\mathrm{Rh}$, and dynamically bent to elliptical shapes using mechanical benders. XANES spectra were collected in fluorescence mode using a Vortex-ME4 Si drift, four-channel array detector (Hitachi HighTechnologies Science Corporation) with an energy resolution of approximately $130 \mathrm{eV}$ for $\mathrm{Ti}$ and $\mathrm{V} K_{\alpha}$ fluorescence peaks. Ca $K_{\alpha} \mathrm{X}$-ray fluorescence data were also acquired.

Samples in the form of polished thin sections or polished mounts were placed on an $x-y-z$ stepping motor stage $\left(100 \mathrm{~nm}\right.$ resolution, positioned at $45^{\circ}$ to the incident beam), allowing the analysis point of interest to be positioned within the monochromatic X-ray beam, as described by Sutton et al. (2005). During data acquisition, the undulator gap, which controls the energy of the fundamental peak in the undulator radiation spectrum, and the monochromator, which controls the excitation energy of fluorescence, were scanned in unison. Typically, XANES spectra were acquired in $0.10 \mathrm{eV}$ monochromator steps from 5400 to $5700 \mathrm{eV}$ for $\mathrm{V}$ and 4900 to $5200 \mathrm{eV}$ for $\mathrm{Ti}$, over the pre-edge and edge region, with a dwell time per energy step of $1 \mathrm{~s}$. Energy calibration was obtained from XANES spectra of $\mathrm{Ti}$ and $\mathrm{V}$ metal foils (EXAFS Materials, Danville, CA). The first peaks in the derivative spectrum were defined to be 5465.0 (V) and 4966.0 (Ti) eV. Each XANES spectrum was normalized by subtracting the pre-edge background well below the edge and normalizing to the count rate at the highest energy within the spectrum. Normalization to the intensity well above the absorption edge eliminates the dependence of the intensity on the total amount of $\mathrm{Ti}$, leaving variations in the pre-edge region dependent only on Ti valence.

For both $\mathrm{Ti}$ and $\mathrm{V}$, the pre-edge peaks were used for valence determinations. Analysis of the pre-edge region was conducted after subtracting the edge step contribution via an interactive spline-fitting routine using manually selected background points. The preedge region consists of several overlapping peaks due to transitions from $1 s$ energy levels to bound 3-D molecular orbitals (e.g., Waychunas 1987); it is the intensities and energies of these features that are valence-sensitive.

The valence of vanadium was determined from the absolute intensity of the pre-edge peak ensemble following the procedure described by Sutton et al. (2005) based on XANES spectra of Fe-, alkali-free haplobasaltic glass standards of Schreiber and Balazs (1982) and the assumption that $\mathrm{V}^{+2}$ in the glass yields no pre-edge peak intensity. Righter et al. (2006) showed that this calibration yields good agreement with known $\mathrm{V}$ valences ranging from 3 to 5 in natural and synthetic crystals. In the present work, $\mathrm{V}^{+2}$ and $\mathrm{V}^{+3}$ are the most relevant for meteoritic samples and these species have pre-edge peak intensities of 0 and 115 , respectively, normalized to an absorption edge step of 1000, i.e., intensities are expressed in permil (Sutton et al. 2005). Our measured V valences, which included data for samples synthesized in air, ranged from 2.5 to 4.8 .

Titanium valence was determined from the normalized intensity and energy of the pre-edge peak ensemble. Titanium K-edge XANES spectra of pure $\mathrm{Ti}^{+4}$-bearing minerals fall into three, distinct valencecoordination positions on a plot of pre-edge peak intensity versus energy (Farges et al. 1997). $\mathrm{Ti}^{+4}$ tet (tetrahedral) has high intensity and low energy; $\mathrm{Ti}^{+4}{ }_{\text {oct }}$ (octahedral) has low intensity and high energy; $\mathrm{Ti}^{+4}$ in fivefold coordination is intermediate. Optical absorption, luminescence, crystal structure refinement, magnetic resonance, and electron paramagnetic resonance studies of clinopyroxene and spinel all lead to the expectation that $\mathrm{Ti}^{+3}$ is predominantly in octahedral coordination (e.g., Dowty and Clark 1973; Lombard et al. 2009), yielding a fourth data cluster at relatively low intensity and low energy (Simon et al. 2007). We used the following standards to define the apices of this valencecoordination field: synthetic forsterite containing $1 \mathrm{wt} \%$ $\mathrm{Ti}$ (all $\mathrm{Ti}^{+4}{ }_{\text {tet }}$; synthesized in air by Jun Ito at the University of Chicago), natural acmite $\left(\mathrm{Ti}^{+4}\right.$ oct Norway), and a synthetic acmite-structured $\mathrm{NaTi}^{+3} \mathrm{Si}_{2} \mathrm{O}_{6}\left(\mathrm{Ti}^{+3}{ }_{\text {oct}}\right.$; Prewitt et al. 1972). The centroid energy and relative intensities ( $\mathrm{E}$ in $\mathrm{eV}$, relative \% $\mathrm{I}$ ) were determined for each of these phases, leading to 
(4969.50, 930), (4970.40, 100), and (4969.50, 76), for $\mathrm{Ti}^{+4}{ }_{\text {tet }}, \mathrm{Ti}^{+4}$ oct, and $\mathrm{Ti}^{+3}$ oct, respectively. The $\mathrm{Ti}^{+4}{ }_{\text {tet }}$ peak overlaps and is more intense than $\mathrm{Ti}^{+3}$ oct.

The slightly nonlinear mixing curves were constrained between pairs of the three endmember components described above (defining the perimeter of the valence field on an "intensity versus energy" plot) by producing and fitting synthetic spectra of known proportions of $\mathrm{Ti}$ species. The relative amounts of $\mathrm{Ti}$ in the different valence states and coordination geometries were obtained by applying the lever rule to the " $\mathrm{Ti}^{+4}{ }_{\text {tet }}-\mathrm{Ti}^{+4}{ }_{\text {oct }}-\mathrm{Ti}^{+3}$ oct" mixing field. Resulting $\mathrm{Ti}$ valences are reported as values between 3 and 4 . Valence uncertainties were determined by applying the uncertainties in energy $( \pm 0.05 \mathrm{eV} ; 1 \sigma)$ and normalized intensity $( \pm 5 \% ; 1 \sigma)$ and inferring the associated valence ranges using the valence-coordination mixing field. Typical $1 \sigma$ errors on the valence are $0.05-0.07$ based on XANES spectral fits.

XANES analyses of spinel were made as single central points (cores), core-rim pairs, and multipoint profiles. For profiles, particular care was taken to select spinels that were large enough to ensure that the XANES sampling area was primarily in spinel over at least a portion of the profile. The excitation volume for XANES analysis is narrow (approximately $2 \mu \mathrm{m}$ ), but deep (23 $\mu \mathrm{m}$ attenuation mean free path in spinel), so $\mathrm{X}$-rays originating from the host material must be considered, particularly for $\mathrm{Ti}$ in spinels included in clinopyroxene, a phase that has 20-50 times more $\mathrm{Ti}$ than does the spinel. Boundary clinopyroxenes (Paque et al. 2009), which often decorate spinel included in melilite, can also be important. We used Ti counts, Ca counts, and spectral shape to gauge the extent of, and to correct for, interference from host phases and boundary clinopyroxene, as discussed below. Contamination of analyses by adjacent melilite or anorthite, or by alteration products (mostly grossular and anorthite), has little effect on the valence ratios for $\mathrm{Ti}$ or $\mathrm{V}$ in spinel because the concentrations of these elements in these phases are much lower than in spinel. As a check, we routinely collected "off-sample" spectra, which showed that mounting epoxy and slide material contributed no significant interferences for determining the valence of $\mathrm{Ti}$ or $\mathrm{V}$ in spinel.

\section{SIMS Measurements of Oxygen and Al-Mg Isotope Analyses}

Oxygen isotopic microanalyses were performed by secondary ion mass spectrometry (SIMS) using the Cameca IMS 1270 instrument at Hokkaido University. The primary ion beam was mass-filtered positive $\mathrm{Cs}^{+}$ ions accelerated to $20 \mathrm{keV}$ and the beam spot size was approximately $3 \mu \mathrm{m}$ in diameter. The primary beam current of approximately $20 \mathrm{pA}$ was used to obtain a count rate of negative ${ }^{16} \mathrm{O}$ ions of approximately $1 \times 10^{7}$ cps. A normal-incident electron gun was utilized for charge compensation of the analysis area. Negative ${ }^{16} \mathrm{O}$ ions were detected by axial Faraday cup, while negative ${ }^{17} \mathrm{O}$ and ${ }^{18} \mathrm{O}$ ions were detected by axial electron multiplier in a magnetic peak jumping mode. A mass resolution power of approximately 5500 was used to separate ${ }^{17} \mathrm{O}$ from ${ }^{16} \mathrm{OH}$. The instrument mass fractionation effect was corrected by utilizing a terrestrial Russian spinel standard. The overall analytical uncertainty is approximately $2 \%$ for $\delta^{17}$, ${ }^{18} \mathrm{O}_{\text {SMOW. }}$. Detailed experimental procedures are described in Wakaki et al. (2013). After analysis, all spots were checked by using the JSM-7000F SEM for overlapping among different minerals or on cracks.

Magnesium isotopic microanalyses were performed by secondary ion mass spectrometry (SIMS) using the Cameca IMS 1270 instrument at Hokkaido University using a $13 \mathrm{keV}{ }^{16} \mathrm{O}^{-}$primary ion beam focused to approximately $10 \mu \mathrm{m}$ diameter. Primary beam current is about 10nA. Detailed experimental procedures are described in Itoh et al. (2008). Measurements were carried out at a mass resolving power of approximately 2000, sufficient to resolve all molecular ion interferences (e.g., ${ }^{24} \mathrm{MgH}^{+},{ }^{48} \mathrm{Ca}^{2+}$ ). Combined contributions from all molecular ion interferences to the measured $\mathrm{Mg}$ isotopic compositions amounted to $<0.1 \%$. Secondary ions were collected by four Faraday cups (designated $\mathrm{L} 2, \mathrm{C}, \mathrm{H} 1$, and $\mathrm{H} 2 *$ ) of the multicollection system: ${ }^{24} \mathrm{Mg}$ for $\mathrm{L} 2,{ }^{25} \mathrm{Mg}$ for $\mathrm{C},{ }^{26} \mathrm{Mg}$ for $\mathrm{H} 1$, and ${ }^{27} \mathrm{Al}$ for $\mathrm{H} 2 *$. Forty cycles of data acquisition for one measurement spot were performed in approximately 7 min. After each sample measurement, we measured background noise of the Faraday cup detectors to compensate for background drift, thereby reducing the systematic error. Russian spinel (SPU) and Takashima augite (Aug) standards were used to correct for instrumental mass fractionation. The sensitivity factors necessary to calculate the $\mathrm{Al} / \mathrm{Mg}$ ratio of the CAI spinel were determined via the SPU standard. Typical overall errors for spinel are estimated to be $\pm 0.2 \%$ o $(2 \sigma)$ for both excess ${ }^{26} \mathrm{Mg}$ and intrinsic mass fractionation $\left(\mathrm{F}_{\mathrm{Mg}}\right)$.

\section{Synthesis Techniques}

Run products from three previously published experimental studies (Stolper 1982; Stolper and Paque 1986; Connolly and Burnett 2003) were analyzed along with one sample synthesized by M. Johnson. Bulk compositions are given in Appendix S1 of the supporting information. "CAI-xx" experimental samples 
Table 1. Experimental results for clinopyroxene run under isothermal conditions.

\begin{tabular}{|c|c|c|c|c|c|c|c|c|}
\hline Sample \# & Temperature $\left({ }^{\circ} \mathrm{C}\right)$ & Time (hrs) & Phases present in run $^{\mathrm{a}}$ & $\log _{10} f \mathrm{O}_{2}$ & $\Delta \mathrm{IW}^{\mathrm{b}}$ & Ti valence & $\begin{array}{l}1 \sigma \text { standard }^{c} \\
\text { deviation }^{\mathrm{c}}\end{array}$ & $\% \mathrm{Ti}^{+3 \mathrm{~d}}$ \\
\hline CAI-62 & 1229 & 96.2 & $\mathrm{gl}+\mathrm{sp}+\mathrm{mel}+\mathrm{an}+\mathrm{cpx}$ & -11.5 & 0.0 & 3.98 & 0.08 & 2 \\
\hline CAI-63 & 1226 & 120 & $\mathrm{sp}+\mathrm{mel}+\mathrm{an}+\mathrm{cpx}$ & -13.8 & -2.6 & 3.79 & 0.07 & 21 \\
\hline CAI-64 & 1227 & 74 & $\mathrm{sp}+\mathrm{mel}+\mathrm{an}+\mathrm{cpx}$ & -15.2 & -3.6 & 3.68 & 0.06 & 32 \\
\hline CAI-66 & 1234 & 23 & $\mathrm{gl}+\mathrm{sp}+\mathrm{mel}+\mathrm{an}+\mathrm{cpx}$ & -16.6 & -5.1 & 3.22 & 0.07 & 78 \\
\hline CAI-65 & 1227 & 29 & $\mathrm{sp}+\mathrm{mel}+\mathrm{an}+\mathrm{cpx}$ & -17.3 & -5.7 & 3.24 & 0.08 & 76 \\
\hline
\end{tabular}

${ }^{\mathrm{a}} \mathrm{gl}=$ glass; $\mathrm{sp}=$ spinel; $\mathrm{mel}=$ melilite; an = anorthite; $\mathrm{cpx}=$ clinopyroxene.

${ }^{\mathrm{b}} \Delta \mathrm{IW}=$ difference (in log units) between the oxygen fugacity of the iron-wüstite buffer (at the temperature of the experiment) and that of the run.

${ }^{\mathrm{c}}$ Error based on counting statistics.

${ }^{\mathrm{d}}$ Percent of Ti that is trivalent.

Table 2. Experimental results for spinel and clinopyroxene from dynamic crystallization experiments run under controlled cooling conditions.

\begin{tabular}{|c|c|c|c|c|c|c|c|c|c|c|}
\hline Sample \# & $\begin{array}{l}\text { Max. } \\
\text { temp. }\left({ }^{\circ} \mathrm{C}\right)\end{array}$ & $\begin{array}{l}\text { Time } \\
@ \mathrm{~T}_{\max } \\
(\mathrm{hrs})\end{array}$ & $\begin{array}{l}\text { Cooling } \\
\text { rate }\left({ }^{\circ} \mathrm{C} / \mathrm{hr}\right)\end{array}$ & $\begin{array}{l}\text { Quench } \\
\text { temp. }\left({ }^{\circ} \mathrm{C}\right)\end{array}$ & $f \mathrm{O}_{2}$ & $\Delta \mathrm{IW}$ & $\begin{array}{l}\text { Phases present } \\
\text { in run }^{\mathrm{a}}\end{array}$ & $\begin{array}{l}\text { XANES- } \\
\text { analyzed } \\
\text { phase }\end{array}$ & Ti valence $^{\mathrm{b}}$ & $\mathrm{V}$ valence \\
\hline $\mathrm{HC} 13$ & 1560 & 3 & 10 & 1505 & Air & 8.1 & $\mathrm{gl}+\mathrm{sp}$ & $\mathrm{sp}$ & 3.86 & 4.83 \\
\hline $\mathrm{HC} 34$ & 1580 & 3 & 10 & 1440 & IW & 0 & $\mathrm{gl}+\mathrm{sp}$ & $\mathrm{sp}$ & $3.49-3.56$ & 2.59 \\
\hline $\mathrm{HC} 14$ & 1566 & 3 & 10 & 1530 & $\mathrm{CCO}^{\mathrm{d}}$ & -6.5 & $\mathrm{gl}+\mathrm{sp}$ & $\mathrm{sp}$ & $3.08-3.19$ & 2.56 \\
\hline \multirow[t]{2}{*}{$\mathrm{HC} 27$} & 1560 & 3 & 10 & 950 & $\mathrm{CCO}$ & -6.5 & $\mathrm{gl}+\mathrm{sp}+\mathrm{mel}+\mathrm{cpx}$ & $\mathrm{sp}$ & $2.94-3.02$ & \\
\hline & & & & & & & & $\operatorname{cpx}$ & $3.25-3.51$ & \\
\hline 1316.4-5 & 1390 & 24 & 5 & $1270^{\mathrm{e}}$ & $\mathrm{CCO}$ & -6.1 & $\mathrm{gl}+\mathrm{sp}+\mathrm{mel}$ & $\mathrm{sp}$ & 3.05 & \\
\hline CAI-224 & 1420 & 3 & 2 & 1171 & Air & 5.0 & $\mathrm{gl}+\mathrm{sp}+\mathrm{mel}+\mathrm{cpx}$ & $\operatorname{cpx}$ & 3.90 & \\
\hline
\end{tabular}

${ }^{\mathrm{a}}$ Abbreviations for phases as used in Table 1

${ }^{\mathrm{b}} 1 \sigma$ Ti valence error ranges from \pm 0.05 to \pm 0.06 .

${ }^{\mathrm{c}} 1 \sigma \mathrm{V}$ valence error is \pm 0.05 .

${ }^{\mathrm{d}} \mathrm{CCO}$ : graphite-CO buffer at a total pressure of $1 \mathrm{~atm}$.

${ }^{\text {e }}$ Sample was held for an $18 \mathrm{hr}$ soak at $1270{ }^{\circ} \mathrm{C}$ prior to quench. All other samples were quenched immediately upon reaching the stated quench temperature.

(Tables 1 and 2) are from isothermal (Stolper 1982) and dynamic crystallization (Stolper and Paque 1986) experiments, respectively; these were conducted on a bulk composition similar to that of the average type B coarse-grained CAI composition reported by Wark (1979). "HCxx" samples (Table 2) were produced by Connolly and Burnett (2003) in dynamic crystallization experiments on a type B1-like bulk composition reported in Beckett et al. (1990). Sample 1316.4-5, which has a liquidus temperature of $1452{ }^{\circ} \mathrm{C}$, was made in a dynamic crystallization experiment conducted by M. Johnson on a spinel-poor (8 $\mathrm{wt} \%$ spinel removed from the bulk composition used by Stolper [1982] and Stolper and Paque [1986]), type B-like composition modeled after glass from sample CAI-2 (Stolper 1982). This experiment and the $\mathrm{CCO}$ experiments of Connolly and Burnett (2003) were run in graphite capsules surrounded by a flowing $\mathrm{CO}$ gas (i.e., at the $\mathrm{CCO}$ buffer).

All experiments were conducted at a total pressure of 1 atmosphere in DelTech 31-VT quench furnaces; see Tables 1 and 2 for run conditions. Temperatures were measured using type $\mathrm{S}$ thermocouples. Experiments under reducing conditions other than $\mathrm{CCO}$ were conducted in flowing $\mathrm{CO}-\mathrm{CO}_{2}$ or $\mathrm{H}_{2}-\mathrm{CO}_{2}$ gas mixtures, with the $f \mathrm{O}_{2}$ measured using an yttria-stabilized zirconia SIRO2 oxygen sensor located adjacent to the sample in the furnace with oxygen as the reference gas (Sato 1971; Badwal et al. 1987); emfs were corrected for electronic conduction using the expression of Mendybaev et al. (1998).

\section{METEORITIC SAMPLES}

A survey of spinels from a suite of CAIs of different types was undertaken with examples from melilite-rich fluffy type A (FTA) and compact type A (CTA) inclusions and melilite-pyroxene-rich type B1 (having a melilite-dominated mantle region) and type B2 (no near-surface enrichment of melilite) inclusions. We analyzed 37 spinels by XANES from eight CAIs from three $\mathrm{CV} 3$ carbonaceous chondrites (Allende, Efremovka, and Vigarano) that had previously been characterized using petrographic, neutron activation, SEM, and EMP techniques (e.g., Sylvester et al. 1993; Paque et al. 2007; Simon et al. 2007). These data are 
Table 3. Results from XANES analyses of spinel in types A and B inclusions.

\begin{tabular}{|c|c|c|c|c|c|c|c|c|c|}
\hline Meteorite & $\begin{array}{l}\text { Inclusion } \\
\text { type }\end{array}$ & Inclusion $^{\mathrm{a}}$ & Spinel \# & Spinel host ${ }^{\mathrm{b}}$ & $\begin{array}{l}\text { Spinel Ti } \\
\text { valence }\end{array}$ & $1 \sigma$ & $\begin{array}{l}\mathrm{TiO}_{2} *{ }^{\mathrm{c}}(\mathrm{wt} \%) \text { in } \\
\text { spinel }\end{array}$ & $\begin{array}{l}\mathrm{TiO}_{2} *(\mathrm{wt} \%) \\
\text { content in } \\
\text { cpx host }\end{array}$ & Comments $^{\mathrm{d}}$ \\
\hline Allende & FTA & A-WP1 & spl & mel & 3.99 & 0.07 & 0.24 & & \\
\hline Allende & FTA & A-WP1 & sp10 & mel & 3.86 & 0.07 & 0.25 & & \\
\hline Allende & FTA & A-WP1 & sp12 & mel & 3.83 & 0.07 & 0.23 & & \\
\hline Allende & FTA & A-WP1 & sp13 & mel & 3.55 & 0.06 & 0.26 & & \\
\hline Allende & FTA & $\mathrm{TS} 24$ & spl & mel & 3.90 & 0.06 & 0.38 & & \\
\hline Allende & FTA & $\mathrm{TS} 24$ & $\mathrm{sp} 2$ & mel & 3.77 & 0.06 & 0.37 & & \\
\hline Allende & FTA & $\mathrm{TS} 24$ & sp3 & alt & 3.79 & 0.05 & 0.40 & & \\
\hline Allende & FTA & $\mathrm{TS} 24$ & sp4 & mel & 3.74 & 0.06 & 0.34 & & \\
\hline Efremovka & CTA & Ef3 & sp1 & mel & 3.75 & 0.06 & 0.47 & & \\
\hline Efremovka & CTA & Ef3 & $\mathrm{sp} 2$ & $\operatorname{cpx}$ & 3.54 & 0.06 & 0.62 & 18.68 & \\
\hline Allende & CTA & TS19 & $\mathrm{sp} 3 \mathrm{c}$ & mel & 3.91 & 0.06 & 0.51 & & \\
\hline Allende & CTA & TS19 & sp3r1 & mel & 3.90 & 0.03 & 0.51 & & \\
\hline Allende & CTA & TS19 & $\mathrm{sp} 8$ & $\mathrm{mel}+\mathrm{pv}$ & 3.98 & 0.06 & 0.52 & & \\
\hline Allende & CTA & TS19 & sp9a & mel & 3.96 & 0.06 & 0.53 & & \\
\hline Allende & CTA & TS19 & sp10 & mel & 3.82 & 0.06 & 0.64 & & \\
\hline Vigarano & B1 & Vig2 & $\mathrm{sp} 1$ & $\operatorname{cpx}$ & 3.31 & 0.05 & 0.23 & 5.5 & \\
\hline Vigarano & B1 & Vig2 & $\mathrm{sp} 2$ & an & 3.43 & 0.05 & 0.26 & & \\
\hline Vigarano & $\mathrm{B} 1$ & Vig2 & sp3 & mantle mel & 3.46 & 0.06 & 0.25 & & \\
\hline Allende & B1 & TS34 & A9 & mantle mel & 4.02 & 0.07 & 0.56 & & 1 \\
\hline Allende & B1 & TS34 & A2 & mantle mel & 3.88 & 0.07 & 0.62 & & 1 \\
\hline Allende & B1 & TS34 & B2 & core mel & 3.92 & 0.07 & 0.235 & & 1 \\
\hline Allende & B1 & TS34 & B3 & $\operatorname{cpx}$ & 3.84 & 0.07 & 0.72 & 8.5 & 1 \\
\hline Allende & B1 & TS34 & B4 & core mel + alt & 3.91 & 0.06 & 0.225 & & 1 \\
\hline Allende & B1 & TS34 & $\mathrm{F} 2$ & an & 3.91 & 0.06 & 0.32 & & 1 \\
\hline Allende & B1 & TS34 & F3 & an & 3.91 & 0.07 & 0.39 & & 1 \\
\hline Allende & $\mathrm{B} 1$ & TS34 & sp1 & $\operatorname{cpx}$ & 3.88 & 0.07 & 0.39 & 5.70 & 1,2 \\
\hline Allende & B1 & TS34 & $\mathrm{sp} 2$ & $\operatorname{cpx}$ & 3.68 & 0.07 & 0.622 & 6.93 & 1,2 \\
\hline Allende & B1 & $\mathrm{TS} 34$ & sp3 & $\mathrm{cpx}$ & 3.87 & 0.07 & 0.721 & 8.15 & 1,2 \\
\hline Allende & B1 & TS34 & $\mathrm{sp} 7$ & $\operatorname{cpx}$ & 3.75 & 0.07 & 0.35 & 4.19 & 1,2 \\
\hline Vigarano & B2 & Vig1 & sp1 & $\operatorname{cpx}$ & 3.39 & 0.06 & 0.25 & 6.56 & \\
\hline Vigarano & B2 & Vig1 & $\mathrm{sp} 2$ & mel & 3.19 & 0.05 & 0.19 & & \\
\hline Vigarano & B2 & Vig1 & sp3 & $\mathrm{cpx}+$ mel & 3.49 & 0.06 & 0.24 & & \\
\hline Vigarano & B2 & Vig1 & sp4 & $\mathrm{cpx}+$ mel & 3.48 & 0.05 & 0.23 & 5.17 & \\
\hline Vigarano & B2 & Vig1 & sp5 & mel & 3.30 & 0.05 & 0.19 & & \\
\hline Allende & B2 & $\mathrm{TS} 21$ & sp4 & $\operatorname{cpx}$ & 3.60 & 0.06 & 0.28 & 3.46 & \\
\hline Allende & B2 & $\mathrm{TS} 21$ & sp5 & $\operatorname{cpx}$ & 3.52 & 0.06 & 0.28 & 2.80 & \\
\hline Allende & B2 & TS21 & sp6 & an & 3.77 & 0.06 & 0.32 & & \\
\hline Allende & B2 & TS21 & $\mathrm{sp} 7$ & mel & 3.80 & 0.06 & 0.335 & & 1 \\
\hline
\end{tabular}

${ }^{a}$ References for petrographic descriptions: A-WP1: Paque et al. (2008); TS24: MacPherson and Grossman (1984); Ef3: Sylvester et al. (1993); TS19: Grossman (1975), Simon et al. (1999); Vig2: Sylvester et al. (1993); TS34: Simon et al. (1991), Paque et al. (2009); Vig1: Sylvester et al. (1993); TS21: Simon and Grossman (2006).

${ }^{\mathrm{b}} \mathrm{pv}=$ perovskite; alt = alteration products; other abbreviations as in Table 1.

${ }^{\mathrm{c}} \mathrm{TiO}_{2}{ }^{*}=$ all $\mathrm{Ti}$ calculated as $\mathrm{TiO}_{2}$ from microprobe analyses.

${ }^{\mathrm{d}}$ Comments: (1) center analysis from XANES and microprobe analyses; (2) clinopyroxene analysis is an average of several points; see also Table 4.

summarized in Table 3. Our primary objectives were to determine the range of $\mathrm{Ti}$ valence among meteoritic spinels from a variety of petrographic settings, to characterize zoning in $\mathrm{Ti}$ valence within spinels, to determine whether or not the valence of spinel depended on the host phase, and to explore possible connections between $\mathrm{Ti}$ valence in the spinel and the $\mathrm{Mg}$ isotopic composition.

\section{RESULTS}

\section{XANES Spectra}

Figure 1 shows typical XANES spectra for clinopyroxene from Allende TS34 (a $\mathrm{Ti}^{+3}$-rich phase) and an included spinel $\left(\mathrm{Ti}^{+4}\right.$-rich phase). The two spectra are different in several primary respects. First, the entire 


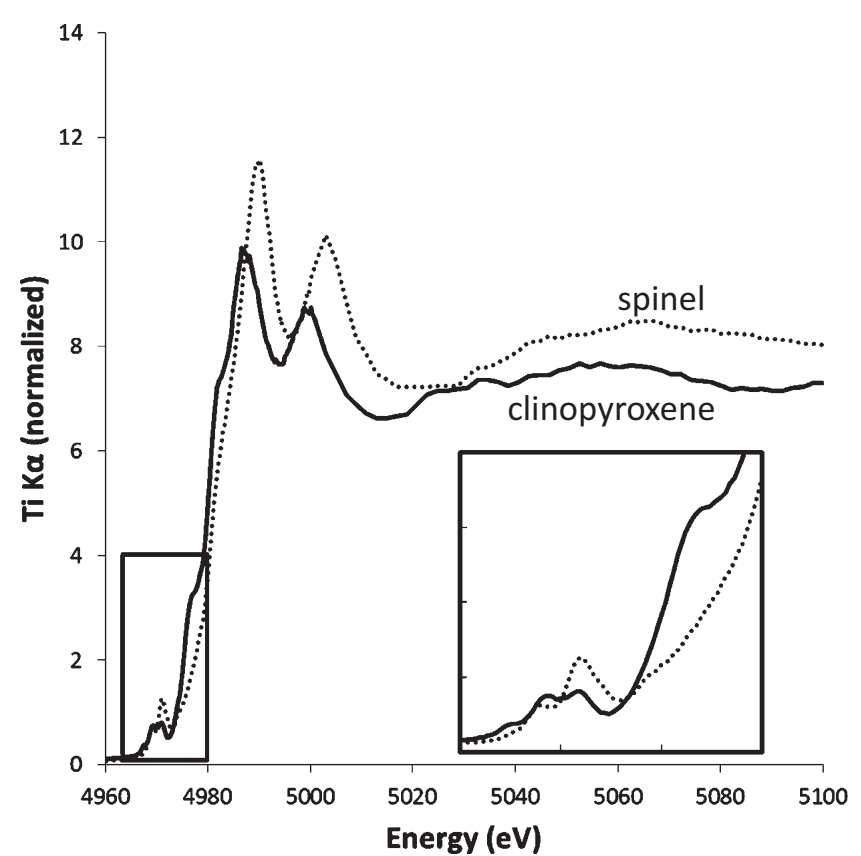

Fig. 1. Intensity of fluoresced $\mathrm{Ti} \mathrm{K}_{\alpha} \mathrm{X}$-rays as a function of photon energy for highly monoenergetic synchrotron radiation. Spectra are depicted for spinel and clinopyroxene grains from Allende inclusion TS34, a type B1 CAI. The preedge portion of the XANES region from 4960 to $4975 \mathrm{eV}$ (inset) is sensitive to the valence of Ti. The XANES spectrum for spinel in the inset is very different from that for the clinopyroxene, and this reflects relatively greater contributions of $\mathrm{Ti}^{+4}$ to the spectrum for spinel and of $\mathrm{Ti}^{+3}$ to that of the clinopyroxene.

spinel spectrum is shifted to higher energy, a result of the higher Ti valence. Second, there are two additional features on the absorption edge of the clinopyroxene spectrum (near $4980 \mathrm{eV}$ ). Third, the pre-edge peak ensembles, on which the valence determinations are based, are distinct (see inset). The pre-edge peak ensemble for the spinel has a higher energy centroid and is dominated by a peak near $4970 \mathrm{eV}$, which is diagnostic of octahedral $\mathrm{Ti}^{+4}$. The overall differences in spectral shape can be useful for constraining the contribution of a host phase to an inclusion spectrum (i.e., for deconvolving a spectrum arising from two phases).

\section{Synthetic Samples}

The major conclusion of this study is that the $\mathrm{Ti}$ in the cores of many CAI spinels is predominately $\mathrm{Ti}^{+4}$, whereas it would be expected to be predominantly trivalent based on redox conditions of CAI formation indicated by the presence of $\mathrm{Ti}^{+3}$-rich clinopyroxene, and the results of experiments (described below) performed under reducing conditions.

We begin an analysis of our experimental data with an assessment of Ti valence in clinopyroxene, because the analyzed crystals are generally large and both $\mathrm{Ti}^{+3}$ - and $\mathrm{Ti}^{+4}$-rich relative to coexisting phases. Analyzed spinels from controlled cooling rate experiments are large enough so that contamination from other phases can generally be neglected. Spinels from the isothermal experiments are, in contrast, quite small ( $8-15 \mu \mathrm{m}$ across) and the sections thick, and we were unable to account quantitatively for contributions to the XANES spectra from adjacent host phases (glass and/or clinopyroxene) that are Ti-rich relative to the spinel. For synthetic spinel, we, therefore, restrict attention to crystals produced in dynamic crystallization experiments.

\section{Ti Valences in Synthetic Clinopyroxene}

Valences of Ti in synthetic clinopyroxene are given in Tables 1 (isothermal experiments) and 2 (dynamic crystallization experiments). The interferences from coexisting phases with the clinopyroxene $\mathrm{Ti}$ spectra are negligible because the grain sizes of analyzed crystals are relatively large $(>100 \mu \mathrm{m}$ for controlled cooling, and $30-50 \mu \mathrm{m}$ for isothermal experiments) and the $\mathrm{Ti}^{+3}$ and $\mathrm{Ti}^{+4}$ contents of clinopyroxene are higher than those of coexisting glass, spinel, melilite, and anorthite. Figure 2 shows pre-edge portions of XANES spectra for clinopyroxene from isothermal run products for various redox conditions calculated as the difference, $\Delta \mathrm{IW}$, in $\log$ $f \mathrm{O}_{2}$ between the gas mixture of the experiment and the iron-wüstite (IW) buffer at the same temperature. Using this parameter as a measure of the redox conditions in an experiment effectively generates a zeroth-order correction for temperature differences between experiments because the temperature dependences of IW and $f \mathrm{O}_{2}$ of constantcomposition $\mathrm{H}_{2}-\mathrm{CO}_{2}$ and $\mathrm{CO}-\mathrm{CO}_{2}$ gas mixtures within a few $\log$ units of IW are similar (although not equal). Also, the deviation between CCO and IW decreases significantly with decreasing temperature for our dynamic crystallization experiments. Note the general decline in intensity of pre-edge peaks of clinopyroxene spectra in Fig. 2 as conditions become more reducing. The spectra for the most reducing conditions (e.g., IW-5.1, IW-5.7) have low energy and low intensity. As $f \mathrm{O}_{2}$ increases, octahedral $\mathrm{Ti}^{+4}$ becomes more prominent, as manifested by the larger peak at around 4970.5 (e.g., IW-3.6). From -3.6 to 0 , tetrahedral $\mathrm{Ti}^{+4}$ becomes apparent, which is observed by a further intensity increase and shift to slightly lower energy. These features all reflect the changing valence and coordination of $\mathrm{Ti}$ in the clinopyroxene as a function of $f \mathrm{O}_{2}$.

For clinopyroxene crystallized from a melt, the $\mathrm{Ti}^{+3} / \mathrm{Ti}^{+4}$ ratio is controlled by equilibrium among clinopyroxene, melt, and vapor. Writing the reaction:

$$
\begin{aligned}
& \mathrm{CaTi}^{+4} \mathrm{Al}_{2} \mathrm{O}_{6(\text { cpx })}(\mathrm{T} 4 \mathrm{P})+\mathrm{SiO}_{2 \text { (liq) }} \\
& \quad=\mathrm{CaTi}^{+3} \mathrm{AlSiO}_{6 \text { (cpx) }} \text { (gross) }+\frac{1}{2} \mathrm{Al}_{2} \mathrm{O}_{3(\text { liq })}+\frac{1}{4} \mathrm{O}_{2(\mathrm{~g})},
\end{aligned}
$$


leads to

$$
\begin{aligned}
\log \left(\frac{X_{\mathrm{gross}}^{\mathrm{cpx}}}{X_{\mathrm{T} 4 \mathrm{P}}^{\mathrm{cpx}}}\right)= & {\left[\log (K)+\log \left(\frac{\gamma_{\mathrm{gross}}^{\mathrm{cpx}}}{\gamma_{\mathrm{T} 4 \mathrm{P}}^{\mathrm{cpx}}}\right)+\log \left(\frac{a_{\mathrm{SiO}_{2}}^{\mathrm{liq}}}{\left(a_{\mathrm{Al}_{2} \mathrm{O}_{3}}^{\operatorname{liq}}\right)^{\frac{1}{2}}}\right)\right] } \\
& -\frac{1}{4} \log f \mathrm{O}_{2}
\end{aligned}
$$

where $K$ is the equilibrium constant; $X_{i}^{j}, \gamma_{i}^{j}$, and $a_{i}^{j}$ are the mole fraction, activity coefficient, and activity of component $i$ in phase $j$, respectively. Gross is the grossmanite component $\left(\mathrm{CaTi}^{+3} \mathrm{AlSiO}_{6}\right)$ in clinopyroxene and $\mathrm{T} 4 \mathrm{P}$ is the $\mathrm{Ti}^{+4}$ endmember clinopyroxene component $\left(\mathrm{CaTi}^{+4} \mathrm{Al}_{2} \mathrm{O}_{6}\right)$. We choose grossmanite and $\mathrm{T} 4 \mathrm{P}$ to be the only Ti-bearing components, so the ratio $X_{\mathrm{gross}}^{\mathrm{cpx}} / X_{\mathrm{T} 4 \mathrm{P}}^{\mathrm{cpx}}$ is equivalent to the molar $\mathrm{Ti}^{+3} / \mathrm{Ti}^{+4}$. If we assume that the bracketed term on the right-hand side of Equation 1 is approximately constant, a plot of $\log \left(\mathrm{Ti}^{+3} / \mathrm{Ti}^{+4}\right)$ in the clinopyroxene as a function of $\log f \mathrm{O}_{2}$ should yield a slope of $-1 / 4$. Figure $3 \mathrm{a}$ shows measured $\log \left(\mathrm{Ti}^{+3} / \mathrm{Ti}^{+4}\right)$ in synthetic clinopyroxene. The isothermal data are all consistent with a $-1 / 4$ slope. Results for one dynamic crystallization experiment (HC27), also shown in Fig. 3a as a gray-shaded region, are in reasonable accord with the isothermal data. A large range in $\Delta \mathrm{IW}$ is encompassed in the figure for $\mathrm{HC} 27$ because, during cooling, the difference between the CCO and IW buffers is not constant (becomes smaller) and because the temperature(s) at which a particular phase crystallized is (are) uncertain. For $\mathrm{HC} 27$, the initial soak was at $1560{ }^{\circ} \mathrm{C}$, at which point the $f \mathrm{O}_{2}$ was IW-6.5, but there was no pyroxene in the charge at that time. As the temperature fell, the difference in $f \mathrm{O}_{2}$ between IW and CCO also fell, reaching IW-3.1 at $950{ }^{\circ} \mathrm{C}$. According to the experiments of Stolper and Paque (1986) conducted in air, clinopyroxene first crystallizes from this bulk composition at approximately $1070{ }^{\circ} \mathrm{C}$, at which point the $f \mathrm{O}_{2}$ of $\mathrm{HC} 27$ was IW-4.2. In Fig. 3a, the gray rectangle labeled $\mathrm{HC} 27$ encloses the two measured valences and their $1 \sigma$ uncertainties and a $\Delta \mathrm{IW}$ interval corresponding to the temperature range of $950-1070{ }^{\circ} \mathrm{C}$. Because it is likely that it is the upper temperature end (lower $\Delta \mathrm{IW}$ ) of this range that is most relevant (i.e., most of the analyzed clinopyroxene crystallized near the initial appearance temperature for this phase), the measured $\mathrm{Ti}^{+3} / \mathrm{Ti}^{+4}$ values are plotted at the lower $\Delta \mathrm{IW}$ of the gray rectangle in Fig. $3 \mathrm{a}$.

\section{Ti Valences of Synthetic Spinel}

Justifications for applying spectra from the standard clinopyroxene endmembers for Ti valence calibration of spinel include the following: (1) The XANES spectrum

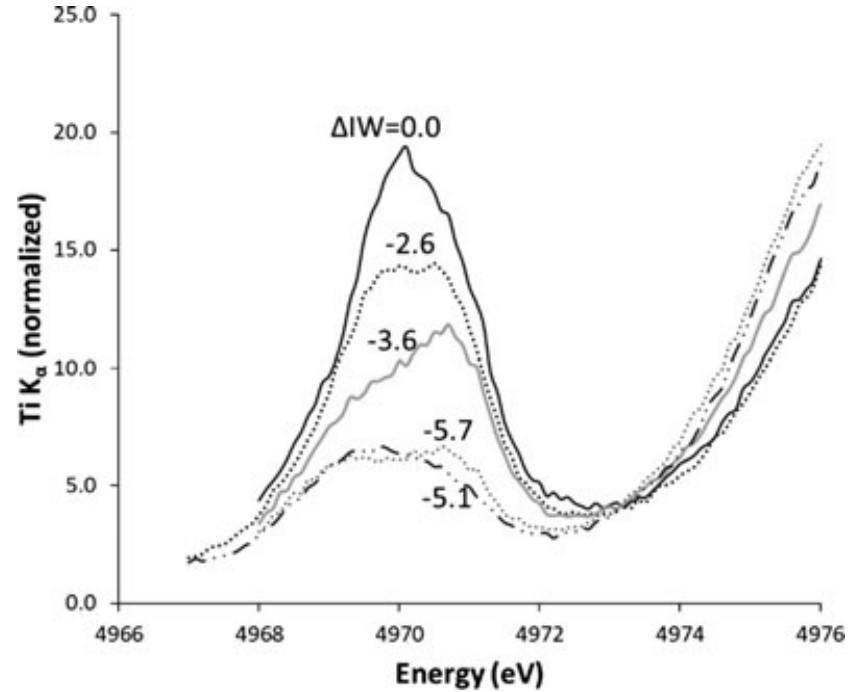

Fig. 2. XANES spectra for synthetic clinopyroxenes grown at 1226-1234 ${ }^{\circ} \mathrm{C}$ and various redox conditions. Individual curves are labeled in terms of $\Delta \mathrm{IW}$, the difference in $\log f \mathrm{O}_{2}$ between the gas mixture used during the experiment and the ironwüstite (IW) buffer at the same temperature. Two partially resolved peaks are present in the XANES region, best displayed in the $\Delta \mathrm{IW}=-2.6$ spectrum. The intensity of the higher energy peak is due to octahedral $\mathrm{Ti}^{+4}$ and the lower energy peak to octahedral $\mathrm{Ti}^{+3}$. As the amount of octahedral $\mathrm{Ti}^{+4}$ increases, intensity of the higher energy peak increases, but it also moves to lower energy (compare $\Delta \mathrm{IW}=-3.6$ to $\Delta \mathrm{IW}=0$ ), thereby obscuring contributions from the lower energy peak associated with $\mathrm{Ti}^{+3}$, even when it is present in significant concentrations. For normalization of the $\mathrm{Ti}$ intensity, the pre-edge background is subtracted from the spectrum and the residual is then normalized to a level taken from the intensity at an energy well above the absorption edge, which is arbitrarily defined as having an intensity of 1000 .

for a large spinel from dynamically crystallized sample $\mathrm{HC13}$, grown in air, closely resembles the endmember clinopyroxene $\mathrm{Ti}^{+4}$ spectrum, giving a $\mathrm{Ti}$ valence of $3.86 \pm 0.07$ (quoted errors are $1 \sigma$ unless otherwise stated) and, (2) based on the clinopyroxene endmembers, XANES spectra for large spinels from samples $\mathrm{HC} 14$ and 1316.4-5, which were synthesized under highly reducing CCO conditions (6-7 log units more reducing than IW), give low Ti valence values, 3.08-3.19 for $\mathrm{HC} 14$ and 3.05 for 1316.4-5 (Table 2), consistent with the bulk of the Ti in the spinel being trivalent, and within uncertainties of being entirely trivalent.

Spinels from the $\mathrm{HC}$ and CAI-224 dynamic crystallization samples (Table 2) are hundreds of $\mu \mathrm{m}$ across, and some are inclusions in melilite, so host phase interference is not an issue in the analysis of these grains. Melt or crystal inclusions in spinel have not been observed and are, presumably, not a factor. For run 

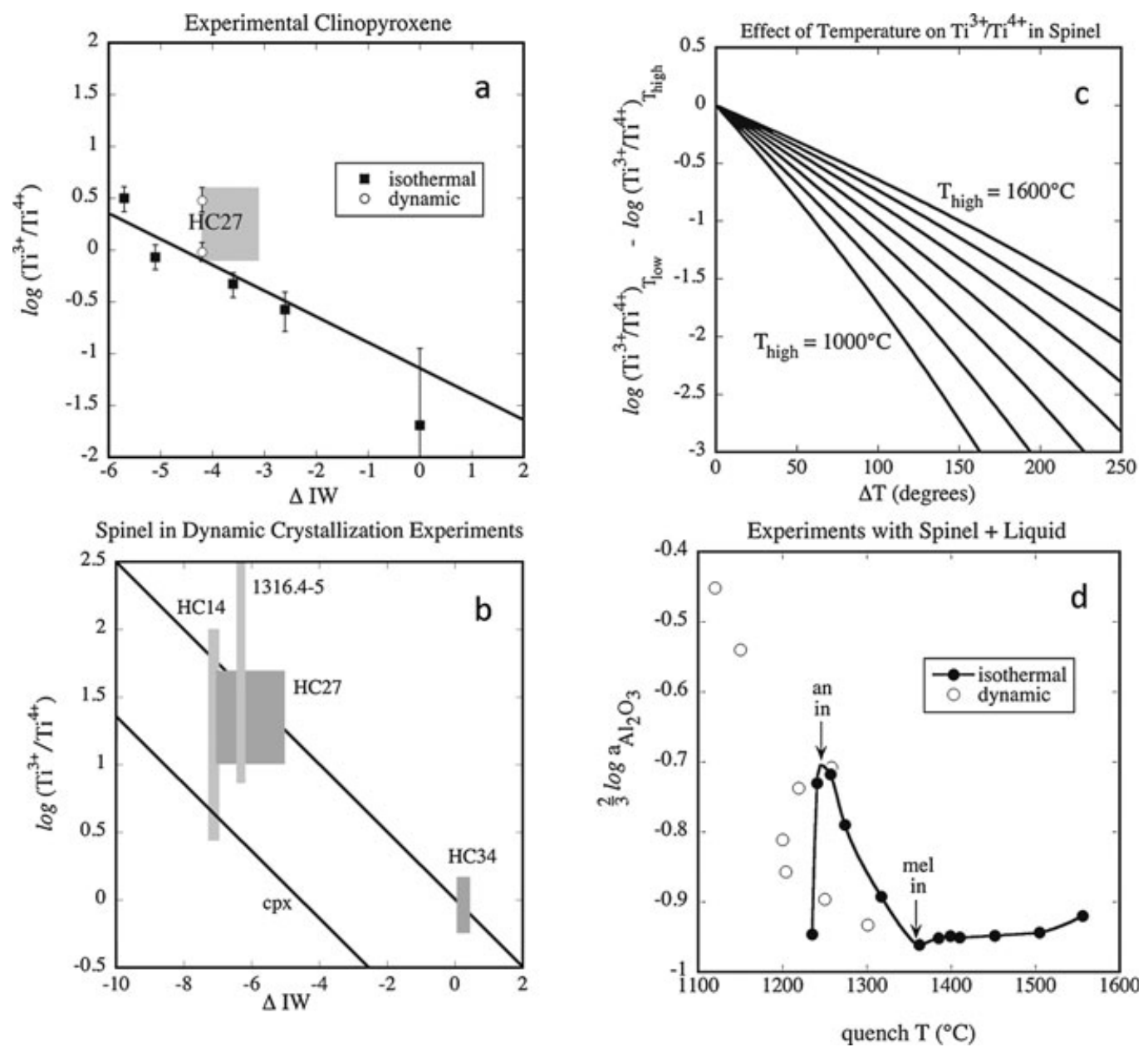

Fig. 3. $\log \left(\mathrm{Ti}^{+3} / \mathrm{Ti}^{+4}\right)$ in synthetic phases as a function of $\Delta \mathrm{IW}$. a) Clinopyroxene. An unweighted regression line is drawn through the four most reduced isothermal data points. The slope, -0.27 , is essentially equivalent to the ideal slope of -0.25 . The gray box labeled HC27 refers to a dynamic crystallization experiment (Table 2). The dimensions of the box encompass the valences and 1-sigma errors for two analyzed pyroxenes and the errors in $\Delta \mathrm{IW}$ due to uncertainties in the estimated appearance temperature of clinopyroxene (see text for elaboration). b) Spinel. Rectangular gray boxes encompass the error in log $\mathrm{Ti}^{+3} / \mathrm{Ti}^{+4}$ and the uncertainty in $\Delta \mathrm{IW}$ due to the range in temperature over which spinel crystallized in an experiment (see text). See Table 2 for temperature differences. Labels refer to the run number (Table 2). A line with a slope of -0.25 is drawn through the data for spinel (all cooling rate experiments). The solid line labeled "cpx" is taken from panel (a) for clinopyroxene. c) Difference in $\log \left(\mathrm{Ti}^{+3} / \mathrm{Ti}^{+4}\right)$ for two CAI liquids differing only in temperature as a function of $\Delta T$, the highest temperature minus the lowest. Curves are labeled with the highest of the two temperatures, $T_{\text {high }}$, and are computed at $100{ }^{\circ} \mathrm{C}$ intervals between 1000 and $1600{ }^{\circ} \mathrm{C}$. Spinel equilibrated with these liquids will have approximately the same $\mathrm{Ti}^{+3} / \mathrm{Ti}^{+4}$ ratios. d) $\frac{3}{2} \log \left(a_{\mathrm{Al} 2 \mathrm{O}_{3}}^{\text {liq }}\right)$, a proxy for variations in $\log \left(\mathrm{Ti}^{+3} / \mathrm{Ti}^{+4}\right)$ as a function of quench temperature based on the model of Berman (1983) for melts coexisting with spinel in the system $\mathrm{CaO}-\mathrm{MgO}-\mathrm{Al}_{2} \mathrm{O}_{3}-\mathrm{SiO}_{2}$. Data are from isothermal experiments of Stolper (1982) and dynamic crystallization experiments of Stolper and Paque (1986).

1316.4-5, two of the selected $10-15 \mu \mathrm{m}$ spinels are hosted by essentially Ti-free melilite, so contributions from the host to the XANES spectra could be neglected, but analyses of a third spinel were discarded because of extensive interference from surrounding glass.

The $\mathrm{Ti}^{+3} / \mathrm{Ti}^{+4}$ ratios of accepted analyses of spinels from dynamic crystallization experiments are higher for more reducing conditions (Table 2; Fig. 3b), as expected. From Fig. 3b, the data are also consistent with a line of slope $-1 / 4$ that is displaced to high $\mathrm{Ti}^{+3} /$ $\mathrm{Ti}^{+4}$ relative to the one for clinopyroxene. Assuming $\mathrm{Ti}$ substitution into normally occupied crystallographic sites rather than defects, it can be shown (see below) that a slope of $-1 / 4$ is to be expected for equilibration of melt and spinel. Note that, for a given $\Delta \mathrm{IW}$, the $\mathrm{Ti}^{+3} / \mathrm{Ti}^{+4}$ ratio in spinel is higher than in clinopyroxene, which is the opposite of what is observed for Allende CAIs.

Interpretation of the dynamic crystallization experiments is not straightforward because of uncertainties regarding the temperature at which the spinel crystallized and the composition of the melt with 
which it equilibrated. The $\mathrm{HC}$ experiments were held for 3 hours at maximum temperatures $\left(1560-1580{ }^{\circ} \mathrm{C}\right)$ above the liquidus $\left(1550{ }^{\circ} \mathrm{C}\right)$, so it is likely that any spinel that grew during heating to the maximum temperature dissolved before cooling and, therefore, the analyzed spinels nucleated at some point during cooling. We do not have a series of equilibration experiments conducted over a range of temperatures and $f \mathrm{O}_{2} \mathrm{~S}$ and we, therefore, take an alternative approach to exploring the effects of changing melt composition, redox conditions, and temperature on $\mathrm{Ti}^{+3} / \mathrm{Ti}^{+4}$ in crystallizing spinel. We do this by first considering the effects of these variables on $\mathrm{Ti}^{+3} / \mathrm{Ti}^{+4}$ in a spinelsaturated melt and then utilize these results to constrain their effect on $\mathrm{Ti}^{+3} / \mathrm{Ti}^{+4}$ in the spinel.

\section{Effect of Temperature and Melt Composition on $\mathrm{Ti}$ Valence in Spinel}

In a melt, valence is controlled through the reduction reaction

$$
\mathrm{TiO}_{2 \text { (liq) }}=\mathrm{TiO}_{\frac{3}{2}(\text { liq })}+\frac{1}{4} \mathrm{O}_{2(\mathrm{~g})}
$$

A free energy of reaction can be derived for this equilibrium and manipulations analogous to those described above for spinel lead to

$$
\begin{aligned}
\log \left(\frac{X_{\mathrm{TiO}_{3 / 2}}^{\mathrm{liq}}}{X_{\mathrm{TiO}_{2}}^{\mathrm{liq}}}\right)= & {\left[-\frac{\mathrm{H}_{\rightarrow(2)}^{\circ}}{2.303 \mathrm{RT}}+\frac{\mathrm{S}_{\rightarrow(2)}^{\circ}}{2.303 R}-\log \left(\frac{\gamma_{\mathrm{TiO}_{3 / 2}}^{\mathrm{liq}}}{\gamma_{\mathrm{TiO}_{2}}^{\operatorname{liq}}}\right)\right] } \\
& -\frac{1}{4} \log f \mathrm{O}_{2}
\end{aligned}
$$

where $X_{i}^{\text {liq }}$ and $\gamma_{i}^{\text {liq }}$ are the mole fraction and activity coefficient, respectively, of component $i$ in the liquid and $\mathrm{H}_{\rightarrow(2)}^{\circ}$ and $\mathrm{S}_{\rightarrow(2)}^{\circ}$ are the enthalpy and entropy of the reaction. If temperature and bulk composition, exclusive of oxygen, are constant and differences in the activity coefficient ratio can be neglected, then Equation 3 predicts that a plot of $\log f^{\mathrm{O}_{2}}$ against $\log \left(X_{\mathrm{TiO}_{3 / 2}}^{\mathrm{liq}} / X_{\mathrm{TiO}_{2}}^{\mathrm{liq}}\right)$ will yield a line with a slope of $-1 / 4$. Slope $-1 / 4$ lines are observed on such plots for melts covering a broad range of bulk compositions (e.g., Johnston 1965; Schreiber et al. 1978; Tranell et al. 2002).

In addition to $f \mathrm{O}_{2}$, temperature can be a major driver for changing $\mathrm{Ti}^{+3} / \mathrm{Ti}^{+4}$ in a constant-composition melt. The Ti reduction reaction 2 is endothermic with $\mathrm{H}_{\rightarrow}^{\circ}$ approximately $293 \mathrm{~kJ} \mathrm{~mol}^{-1}$ according to the results of Schreiber et al. (1978) for two liquid compositions in the system $\mathrm{CaO}-\mathrm{MgO}-\mathrm{Al}_{2} \mathrm{O}_{3}-\mathrm{SiO}_{2}-\mathrm{TiO}_{\mathrm{x}}$. This means that the $\mathrm{Ti}^{+3} / \mathrm{Ti}^{+4}$ ratio decreases with decreasing temperature at constant melt composition. There are no data for activity coefficients of the Ti-bearing liquid components given in Equation 3 for CAI-like liquids, but $\gamma_{\mathrm{TiO}_{32}}^{\mathrm{liq}} / \gamma_{\mathrm{TiO}_{2}}^{\mathrm{liq}}$ is independent of temperature, at least for liquids in the $\mathrm{CaO}-\mathrm{SiO}_{2}-\mathrm{TiO}_{\mathrm{x}}$ system (Tranell et al. 2002). Figure 3c shows the difference in $\log \left(X_{\mathrm{TiO}_{3 / 2}}^{\mathrm{liq}} / X_{\mathrm{TiO}_{2}}^{\mathrm{liq}}\right)$ between two melts of constant $f \mathrm{O}_{2}$ and composition exclusive of oxygen, but at different temperatures as a function of the difference between the two temperatures. If the ratio of spinel-liquid partition coefficients for $\mathrm{Ti}^{+3}$ to that for $\mathrm{Ti}^{+4}$ is independent of temperature, these differences will be the same for spinel. That is, if $\mathrm{Ti}^{+3} / \mathrm{Ti}^{+4}$ in a melt rises due to a change in temperature and melt composition, then $\mathrm{Ti}^{+3} / \mathrm{Ti}^{+4}$ in a coexisting spinel that equilibrates with that melt will rise by the same amount. From Fig. 3c, the enthalpy effect can be substantial, given the relatively large temperature range over which spinel can crystallize in CAI-like bulk compositions (e.g., Stolper 1982; Stolper and Paque 1986). For example, $\mathrm{Ti}^{+3} / \mathrm{Ti}^{+4}$ of a spinel equilibrated with a particular melt at $1400{ }^{\circ} \mathrm{C}$ and a given $f \mathrm{O}_{2}$ would be $1.8 \log$ units higher than one from the same melt equilibrated at the same $f \mathrm{O}_{2}$, but at $1200{ }^{\circ} \mathrm{C}$ (i.e., $200^{\circ}$ lower).

The above analysis assumes that the melt does not change composition except for oxygen content and that the oxygen fugacity does not change with temperature (i.e., the purpose was to isolate effects of temperature from those of melt composition and $f \mathrm{O}_{2}$ ). A fractionally crystallizing liquid changes composition, however, due to the removal of crystalline solids from the melt and an evaporating melt changes composition because the more volatile elements $(\mathrm{Mg}, \mathrm{Si}$, and $\mathrm{O}$ ) are lost from the melt. We can assess the effect of melt composition on $\mathrm{Ti}^{+3} / \mathrm{Ti}^{+4}$ in spinel by considering the reaction

$$
\begin{aligned}
& \mathrm{MgTi}^{+3} \mathrm{AlO}_{4(\mathrm{sp})}+\mathrm{MgAl}_{2} \mathrm{O}_{4(\mathrm{sp})}+\frac{1}{4} \mathrm{O}_{2(\mathrm{~g})} \\
& =\mathrm{Mg}_{2} \mathrm{TiO}_{4(\mathrm{sp})}+\frac{3}{2} \mathrm{Al}_{2} \mathrm{O}_{3(\text { liq })} .
\end{aligned}
$$

Let $K^{\prime}$ be the equilibrium constant for this reaction, a function of temperature, but not of composition. In an analysis analogous to those used above for Equations 1 and 3, we obtain

$$
\begin{aligned}
\log \left(\frac{X_{\mathrm{MgTiAlO}_{4}}^{\mathrm{sp}}}{X_{\mathrm{Mg}_{2} \mathrm{TiO}_{4}}^{\mathrm{sp}}}\right)=[ & -\log K^{\prime}+\log \left(\frac{\gamma_{\mathrm{Mg}_{2} \mathrm{TiO}_{4}}^{\mathrm{sp}}}{\gamma_{\mathrm{MgTiAlO}_{4}}^{\mathrm{sp}} a_{\mathrm{MgAl}_{2} \mathrm{O}_{4}}^{\mathrm{sp}}}\right) . \\
& \left.+\log \left(a_{\mathrm{Al}_{2} \mathrm{O}_{3}}^{\mathrm{liq}}\right)^{\frac{3}{2}}\right]-\frac{1}{4} \log f \mathrm{O}_{2}
\end{aligned} .
$$

The left-hand side of Equation 4 is equivalent to $\log \left(X_{\mathrm{Ti}^{+3}} / X_{\mathrm{Ti}^{+4}}\right)$ in the spinel. For constant temperature and melt composition (other than oxygen and, hence, 
$\left.\mathrm{Ti}^{+3} / \mathrm{Ti}^{+4}\right)$, a plot of $\log f \mathrm{O}_{2}$ against $\log \left(\mathrm{Ti}^{+3} / \mathrm{Ti}^{+4}\right)$ in spinel will yield a straight line with a slope of $-1 / 4$, provided the middle term in the brackets on the righthand side of the equation is constant. The term $\left(a_{\mathrm{Al}_{2} \mathrm{O}_{3}}^{\text {liq }}\right)$, which also occurs on the right-hand side of Equation 4 , is at most very weakly dependent on $f \mathrm{O}_{2}$ for CAI-like liquids (i.e., $\mathrm{Ti}^{+3} / \mathrm{Ti}^{+4}$ has little influence on the activity of alumina), but it can be a strong function of liquid composition if ratios of the major element oxides vary (e.g., due to crystallization) and it is to this issue that we, finally, turn.

For spinel, the influence of melt composition on valence can be seen through Equation 4, which implies that $\log \left(\mathrm{Ti}^{+3} / \mathrm{Ti}^{+4}\right)$ in the spinel scales with $\frac{3}{2} \log \left(a_{\mathrm{Al}_{2} \mathrm{O}_{3}}^{\text {liq }}\right)$ in the melt at constant temperature and $f \mathrm{O}_{2}$. This parameter, as calculated from the model of Berman (1983) for melts coexisting with spinel \pm melilite in the system $\mathrm{CaO}-\mathrm{MgO}-\mathrm{Al}_{2} \mathrm{O}_{3}-\mathrm{SiO}_{2}$, is plotted against temperature in Fig. 3d. The activity of alumina in a crystallizing CAI-like melt is an apparent function of temperature because the melt changes composition. At high temperatures, spinel fractionation leads to small changes in the activity of alumina and, therefore, of $\mathrm{Ti}^{+3} / \mathrm{Ti}^{+4}$. During crystallization of melilite, however, $\left(a_{\mathrm{Al}_{2} \mathrm{O}_{3}}^{\text {liq }}\right)^{3 / 2}$ may increase by as much as a factor of five (i.e., before anorthite and/or clinopyroxene crystallize). Note that this melt composition effect acts in a direction opposite to the enthalpy effect described above, so that the net change in valence depends on details of how the crystallizing phase assemblage and $f \mathrm{O}_{2}$ change with temperature. Note also that there is a reversal in the isothermal data at low temperatures with the appearance of anorthite, implying that there may be reversals to lower values of $\mathrm{Ti}^{+3} / \mathrm{Ti}^{+4}$ in the melt associated with crystallization of anorthite, especially if it occurs over a small range in temperature and $f \mathrm{O}_{2}$. This shift in alumina activity happens after almost all of the spinel has crystallized, but it could affect $\mathrm{Ti}$ valence in spinel rims.

\section{Summary of Experiments}

Figures $3 \mathrm{a}$ and $3 \mathrm{~b}$ show that, during crystallization of Type B CAI liquids, XANES-measured Ti valences decrease with decreasing $f \mathrm{O}_{2}$ for both spinel and clinopyroxene. These are the expected trends; however, the results in Figs. $3 \mathrm{a}$ and $3 \mathrm{~b}$ are important in showing that the measured $\mathrm{Ti}^{+4}$-rich spinels from CAIs (next section) are not the result of some anomalously low partition coefficient for $\mathrm{Ti}^{+3}$ in spinel or of a misinterpretation of the XANES spectra due to our use of clinopyroxene standards for $\mathrm{Ti}$ valence endmembers.
The data in Figs. $3 \mathrm{a}$ and $3 \mathrm{~b}$ are directly measured on type B CAI compositions and thus directly comparable to meteoritic CAIs; variations in temperature and composition on $\mathrm{Ti}^{+3} / \mathrm{Ti}^{+4}$ are covered. Figures $3 \mathrm{c}$ and $3 \mathrm{~d}$ are of fundamental interest in isolating the effects of temperature and melt composition on $\mathrm{Ti}^{+3} / \mathrm{Ti}^{+4}$.

\section{XANES Analyses of Meteoritic Spinels}

Interpretation of XANES spectra for spinels included in melilite, alteration products, and anorthite is straightforward because these hosts are Ti-poor, and the observed XANES spectra are essentially those of spinel. Interpretation of the XANES spectra for clinopyroxenehosted spinels is complicated by the presence of a host phase with considerably more $\mathrm{Ti}$ than the included spinel. For all spinel-host pairs, we were careful to analyze the cores of spinels to minimize contributions from host grains. These core analyses of individual spinels provide an overview of the population of grains within a CAI. For larger grains, we also obtained traverses, providing details concerning zoning in $\mathrm{Ti}^{+3} /$ $\mathrm{Ti}^{+4}$.

\section{Analyses of Spinel Cores}

Analyses of spinel cores are summarized in Table 3 and illustrated, for type B inclusions, in Fig. 4a. Identities of the host phases of the analyzed grains are given in Table 3 along with average values of host clinopyroxene $\mathrm{TiO}_{2}{ }^{*}$. The range in $\mathrm{TiO}_{2}{ }^{*}$ of host clinopyroxene surrounding spinel in larger TS34 clinopyroxene grains is given in Table 4.

For the type B data (Fig. 4a), we can distinguish two groups. TS34 spinels define a large field of high valence, 3.7-4.0, and variable $\mathrm{TiO}_{2}{ }^{*}$, ranging from 0.23 to $0.72 \%$. Valence for spinels in three other type B inclusions ranges from 3.2 to 3.8 ; these data plot on a line in Fig. 4a $\left(r^{2}\right.$ for an unweighted linear regression is 0.89), independent of spinel host phase (anorthite, clinopyroxene, melilite) or, in the case of Vig2 (B1), whether the host melilite is in the CAI core or mantle. These features argue against analytical artifacts due to host phase contributions. The primary synchrotron radiation photons are deeply penetrating, and possible contributions to the Ti XANES spectra for small spinel inclusions in clinopyroxene hosts can seriously complicate these analyses because clinopyroxene $\mathrm{Ti}$ concentrations are typically 10-20 times higher than in spinel. If this line were an artifact of clinopyroxene contamination, we would expect a negative slope, with the low-valence endmember having relatively high $\mathrm{TiO}_{2}$ * Although the ubiquitous boundary clinopyroxenes decorating the surfaces of melilite-hosted spinel are Ti-rich, their contributions to the Ti signals 

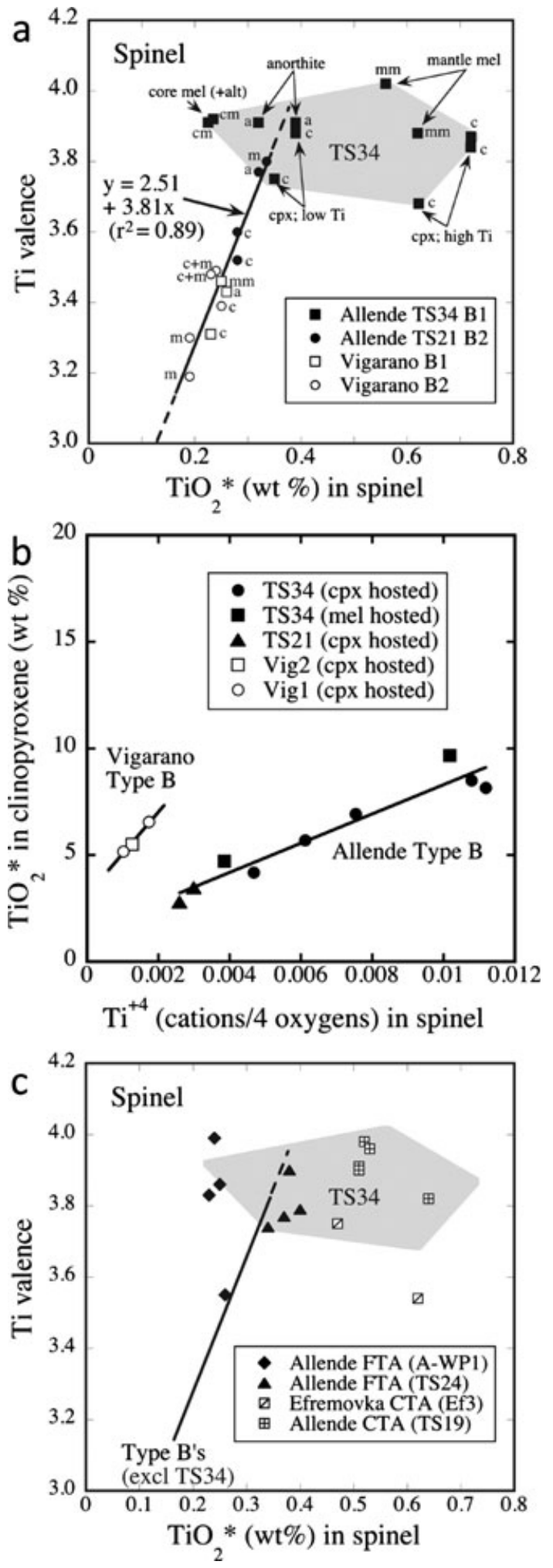

for core XANES analyses are generally small (see Appendix S3 of the supporting information). Overall, the fact that both clinopyroxene- and anorthite/melilitehosted spinels are consistent with the same positively
Fig. 4. a) Titanium valence in the cores of spinel grains from type B CAIs that are included in both low-Ti (melilite, anorthite, alteration) and high-Ti (clinopyroxene) host phases as a function of $\mathrm{wt} \% \mathrm{TiO}_{2} *$, the bulk $\mathrm{Ti}$ content in the spinel expressed as $\mathrm{TiO}_{2}$. Host phase is indicated adjacent to each point ( $\mathrm{a}=$ anorthite; $\mathrm{c}=$ clinopyroxene; $\mathrm{m}=$ melilite (type $\mathrm{B} 2$ ); $\mathrm{cm}=$ core melilite (type $\mathrm{B} 1) ; \mathrm{mm}=$ mantle melilite (type B1); $\mathrm{c}+\mathrm{m}=$ both clinopyroxene and melilite). A gray region encloses all data from TS34. An unweighted regression line, Ti valence $=2.51+3.81 * \mathrm{TiO}_{2} *(\mathrm{wt} \%) ; \mathrm{r}^{2}=0.89$, is shown for all data from Vig1 (B2), Vig2 (B1), and Allende TS21 (B2). b) Weight $\% \mathrm{TiO}_{2} *$ in adjacent clinopyroxene as a function of $\mathrm{Ti}^{+4}$ cations in spinel for type $\mathrm{B}$ inclusions. Clinopyroxene compositions for melilite-hosted spinels are from boundary clinopyroxenes. An unweighted regression line through all of the Allende data is also shown (weight $\% \mathrm{TiO}_{2}{ }^{*}$ in clinopyroxene $=1.45+684.7 *$ cations $\mathrm{Ti}^{+4}$ per 4 oxygens in spinel; $\left.r^{2}=0.93\right)$. The line through the Vigarano data is strictly for visual convenience. c) Titanium valence in the center of spinel grains from type A CAIs as a function of $\mathrm{wt}^{\%} \mathrm{\textrm {TiO } _ { 2 }}$. The high- $\mathrm{TiO}_{2}{ }^{*}$, low-valence grain from Ef3 is an inclusion in clinopyroxene. All other grains are inclusions in melilite. Also shown is the regression line for spinels in type B inclusions TS21, Vig1, and Vig2 (solid line) and a shaded field for the Allende type B1 inclusion TS34, both taken from panel a.

sloped line also suggests that the observed correlation is not an artifact of clinopyroxene contamination. Moreover, although clinopyroxene-hosted spinel has a lower valence than spinel in melilite or anorthite in Vig2 (B1) and TS21 (Allende B2), the valence of spinel in melilite is lower than that in clinopyroxene in Vig1 (B2). The trend in Fig. 4a appears to apply in both type B1 and type $\mathrm{B} 2$ inclusions.

Note also that the simple addition of $\mathrm{Ti}^{+4}$ to $\mathrm{a} \mathrm{Ti}^{+3}$ rich spinel would yield a curve asymptotic to a valence of 4 , which is not observed at least up to a valence of 3.8. It is significant that the correlation has a positive slope, with the low-valence endmember being low in $\mathrm{TiO}_{2}{ }^{*}$.

Data for TS34 spinels are quite different from those for the other type Bs. For two of the clinopyroxenehosted spinels, those having the lowest $\mathrm{TiO}_{2}{ }^{*}$ values, compositions are consistent with the line describing data for Vig1, Vig2, and TS21. Compositions of the remaining three clinopyroxene-hosted spinels, with high $\mathrm{TiO}_{2}{ }^{*}$, are inconsistent with this line (Fig. 4a). This difference is apparently connected to the Ti content of the host. The low- $\mathrm{TiO}_{2}{ }^{*}$ spinels from $\mathrm{TS} 34$ are in low$\mathrm{TiO}_{2} *$ clinopyroxene and the high- $\mathrm{TiO}_{2} *$ spinels are hosted by higher $\mathrm{TiO}_{2} *$ clinopyroxenes (Table 4). The data of Simon et al. (1991, 2007) suggest that, in clinopyroxene in type B1 CAIs, valence increases as Ti content decreases. This is not the case for large spinel inclusions in clinopyroxene (Fig. 4a), as relatively Tirich spinel in Ti-rich clinopyroxene has the same valence as Ti-poor spinel in Ti-poor clinopyroxene. 
Table 4. Comparison of single-point Ti valence in clinopyroxene hosts and included spinels analyzed by XANES from Allende TS34.

\begin{tabular}{|c|c|c|c|c|}
\hline Spinel \# & $\begin{array}{l}\text { Ti valence in } \\
\text { spinel by XANES }\end{array}$ & $\begin{array}{l}\mathrm{TiO}_{2} *(\mathrm{wt} \%) \text { in spinel, } \\
\text { electron microprobe }\end{array}$ & Ti valence in cpx & $\begin{array}{l}\mathrm{TiO}_{2}^{*} \\
(\mathrm{wt} \%) \text { in cpx, electron } \\
\text { microprobe } \\
\text { (number of analyses) }\end{array}$ \\
\hline TS34 sp1 & 3.88 & 0.39 & $3.313^{\mathrm{b}}$ & $4.36-6.55(5)$ \\
\hline TS34 sp2 & 3.68 & 0.622 & $3.125^{\mathrm{b}}$ & $4.66-8.31(7)$ \\
\hline TS34 sp3 & 3.87 & 0.721 & $3.202^{\mathrm{b}}$ & $7.16-9.56(5)$ \\
\hline TS34 sp7 & 3.75 & 0.35 & $3.222^{\mathrm{b}}$ & $3.53-4.64(6)$ \\
\hline TS34 B3 & 3.84 & 0.72 & $3.04^{\mathrm{c}}$ & $8.1-8.75^{\mathrm{d}}$ \\
\hline
\end{tabular}

${ }^{\mathrm{a}}$ Calculated based on stoichiometry from electron microprobe analyses.

${ }^{\mathrm{b}}$ Core analysis.

${ }^{c}$ XANES analysis.

${ }^{\mathrm{d}}$ Approximate values for clinopyroxene in the vicinity of spinel obtained from microprobe analyses designed for trace element analysis of spinels ( $\mathrm{Mg}$ and $\mathrm{Al}$ fixed to stoichiometric values).

Clinopyroxene hosts from the other type Bs are all relatively low in $\mathrm{TiO}_{2} *\left(2.8-6.6 \mathrm{wt} \% \mathrm{TiO}_{2}{ }^{*}\right)$.

Data for anorthite-hosted spinels in TS34 are plausibly close to the Vig1-Vig2-TS21 regression shown in Fig. 4a, but spinel enclosed in core melilite (low $\mathrm{TiO}_{2} *$ ), mantle melilite (high $\mathrm{TiO}_{2}{ }^{*}$ ), and clinopyroxene (high $\mathrm{TiO}_{2}{ }^{*}$ ) plot far off the line. In contrast, melilitehosted spinels in Vig1, Vig2, and TS21 appear to be consistent with the line. We conclude that, regardless of host phase, the Ti valence in cores of TS34 spinels is generally high relative to expectations based on results for spinels from the other three analyzed type B inclusions.

Spinels included in melilite from TS34 generally have thin, $1-2 \mu \mathrm{m}$ rinds or blebs of clinopyroxene on the spinel, which Paque et al. (2009) referred to as "boundary clinopyroxenes." We have not conducted a detailed survey of these occurrences for the present work, but we obtained compositions of boundary clinopyroxenes adjacent to four melilite-hosted spinels in the mantle and one melilite-hosted spinel in the core, $\mathrm{B} 2$. $\mathrm{TiO}_{2} *$ ranges from 9 to $13 \mathrm{wt} \%$ in boundary pyroxene on the mantle melilite spinel $(9.7 \mathrm{wt} \%$ for A9) and 3-8 wt\% in boundary clinopyroxene on B2 (average $5 \mathrm{wt} \%$ ). If the single analysis of spinel $\mathrm{B} 2$ is representative, boundary clinopyroxenes around spinels in core melilite are lower in $\mathrm{Ti}$ than those in the mantle, just as there is lower $\mathrm{TiO}_{2}{ }^{*}$ in the spinels included in core melilite (see also Connolly et al. 2003).

Analogous to correlations noted in previous studies (e.g., Connolly et al. [2003] and references therein), there is a linear relationship between $\mathrm{TiO}_{2}{ }^{*}$ of a clinopyroxene host and $\mathrm{Ti}^{+4}$ in a spinel inclusion, and this is particularly well developed in TS34 (Fig. 4b). Most of the variation in $\mathrm{TiO}_{2}{ }^{*}$ in clinopyroxene phenocrysts from type $\mathrm{B}$ inclusions is due to variations in $\mathrm{Ti}^{+3}$ contents (Simon et al. 1991, 2007), so $\mathrm{TiO}_{2}{ }^{*}$ can be thought of as a rough proxy for variations in $\mathrm{Ti}^{+3}$, which implies that $\mathrm{Ti}^{+4}$ in spinel is correlated with $\mathrm{Ti}^{+3}$ in host clinopyroxene. $\left(\right.$ For $\mathrm{TiO}_{2}{ }^{*}$ contents in clinopyroxene less than approximately $4 \%$, it is not possible to accurately calculate $\mathrm{Ti}^{+4}$ and $\mathrm{Ti}^{+3}$ proportions from electron microprobe analyses.) The average compositions of two analyzed boundary clinopyroxenes around spinel inclusions in melilite (closed squares in Fig. 4b) both plot slightly above the TS34 regression line, but are reasonably consistent with it. The Vigarano data, which are well off the Allende trend, appear to lie on a different line.

Vigarano is a member of the "reduced" group of CV3 chondrites and Allende is a member of the "oxidized" group. Group designation is based on observations of features, such as metal/magnetite ratios, that are affected by low-temperature parent body processes that were unlikely to have affected the valence of $\mathrm{Ti}$ in spinels. There are parent body effects discernible, for example, in the small amounts of iron present in some TS34 spinel grains (Paque et al. 2007), but the effect on Ti valence can be neglected.

Figure $4 \mathrm{c}$ shows $\mathrm{Ti}$ valence in spinel as a function of $\mathrm{TiO}_{2}{ }^{*}$ for type A inclusions. Analyzed spinels from FTAs (Allende A-WP1 and TS24) have lower $\mathrm{TiO}_{2}$ * concentrations than do those from the CTAs (Efremovka Ef3 and Allende TS19). Valences of most of the grains exceed 3.7, comparable to values obtained from Allende type Bs (Fig. 4a), although there are two grains with substantially lower valence. One of these, from CTA Ef3, is enclosed in very Ti-rich clinopyroxene $\left(\mathrm{TiO}_{2}{ }^{*}=18.7 \mathrm{wt} \%\right)$ and it is possible that the low valence reflects clinopyroxene interference. All other spinels in Fig. 4c are melilite-hosted. The low-valence 

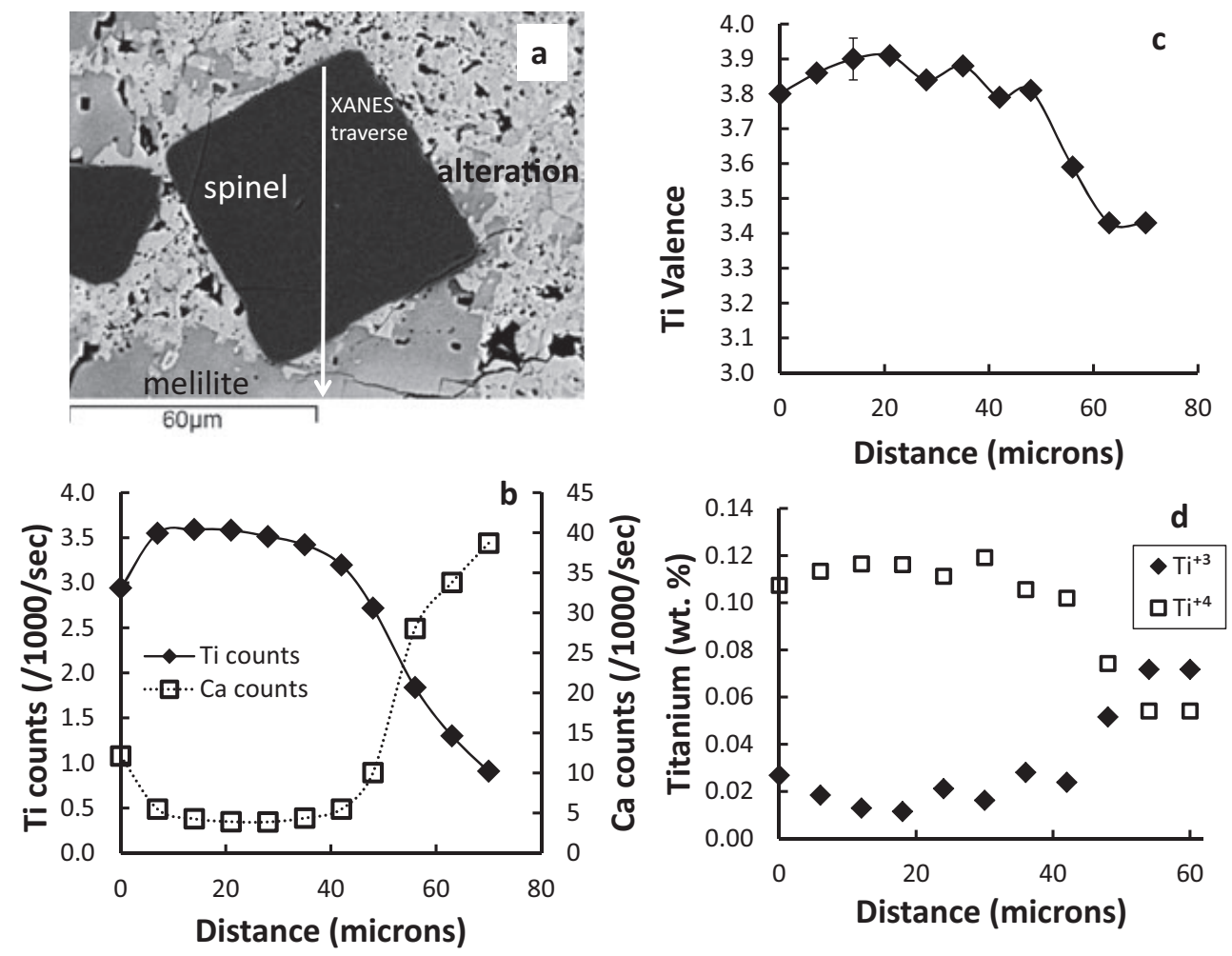

Fig. 5. Titanium count rates and valence in spinel grain B4, which is included in a mixture of melilite and alteration products from the core of Allende Type B1 inclusion TS34. a) Backscattered electron (BSE) photomicrograph with the position and direction of the XANES traverse indicated by a white arrow. Scale bar is $60 \mu \mathrm{m}$. b) Ti and Ca counts per second as a function of distance along the traverse indicated in panel a. Note that the last three points have much higher Ca counts than the others, indicating contamination by a Ca-rich phase. Two additional points, at 0 and $48 \mu \mathrm{m}$, show elevated, but lesser, Ca contributions. c) Ti valence as a function of distance for the traverse indicated in panel a. The mean valence for the four points (16-36 $\mu \mathrm{m})$ in the central, low-Ca portion of the traverse is $3.88 \pm 0.04$. Representative $1 \sigma$ error bar shown. $\mathrm{d}^{2} \mathrm{Weight}_{\mathrm{O}} \mathrm{Ti} \mathrm{Ti}^{+3}$ and $\mathrm{Ti}^{+4} \mathrm{in}^{-}$ spinel as a function of distance along the traverse indicated in panel (a). These concentrations were obtained by combining Ti valence determined by XANES (panel c) with EPMA analyses for total Ti. The asymmetries apparent in variations of concentration as a function of distance in panels $b-d$ are a consequence of beam orientation and crystal geometry (see text and Fig. 6).

spinel, from A-WP1, has essentially the same $\mathrm{TiO}_{2}$ * concentration as the other three analyzed spinels from this inclusion, leading to a large range in valence, 3.64.0, with little variation in $\mathrm{TiO}_{2}{ }^{*}$. Contamination of the analysis by perovskite, which is sometimes observed in contact with spinel in type A CAIs, would have increased both $\mathrm{TiO}_{2}{ }^{*}$ and valence. The observed compositions of A-WP1 spinels may be a fortuitous consequence of grain selection, but they may also reflect an oxidation reaction in which there is no exchangeable Ti-bearing phase present. This would be governed by a reaction such as

$$
16 \mathrm{MgAl}_{2} \mathrm{O}_{4}+3 \mathrm{Ti}_{\frac{8}{3}} \mathrm{O}_{4}+2 \mathrm{O}_{2}=8 \mathrm{Mg}_{2} \mathrm{Ti}^{+4} \mathrm{O}_{4}+12 \mathrm{Al}_{\frac{8}{3}} \mathrm{O}_{4}
$$

where all reactants except $\mathrm{O}_{2}$ are spinel components. For the CTAs, the scatter in Fig. 4c is reminiscent of the mantle melilite and high- $\mathrm{TiO}_{2} *$ spinels hosted by clinopyroxene in TS34 (Fig. 4a).

\section{Valence Profiles}

TS34 is highly unusual among type B CAIs in having large spinels, up to $100 \mu \mathrm{m}$ across, making them attractive candidates for the determination of possible zoning with respect to $\mathrm{Ti}^{+3} / \mathrm{Ti}^{+4}$. We measured profiles across seven isolated spinel grains with low-Ti hosts in TS34, one profile across a series of at least four attached spinels in TS21, and one profile of a spinel inclusion in clinopyroxene from TS34. We describe five of the TS34 profiles in detail here. The TS21 spinel profile and two traverses across a pair of spinels included in single anorthite grains in TS34 give similar results; the latter data are included in Appendix S2 of the supporting information.

Spinel B4 is located in an intergrowth of melilite and alteration products in the core of TS34. The immediate petrographic setting is shown in Fig. 5a 
along with the location of the XANES traverse. Figure $5 \mathrm{~b}$ shows raw $\mathrm{Ti}$ and $\mathrm{Ca}$ count rates from the XANES analyses, and the Ti valence profile is shown in Fig. 5c. Figure 5d shows $\mathrm{Ti}(\mathrm{wt} \%)$ in the spinel computed from XANES and EMP data separately for $\mathrm{Ti}^{+3}$ and $\mathrm{Ti}^{+4}$. Taken at face value, the downturns in $\mathrm{Ti}$ valence near the beginning and end of the profile indicate that the spinel is zoned with respect to $\mathrm{Ti}^{+3} /$ $\mathrm{Ti}^{+4}$, with $\mathrm{Ti}$ valence decreasing near the rim of the crystal. Note, however, that $\mathrm{Ti}$ and $\mathrm{Ca}$ are anticorrelated at the ends of the profile, and that the $\mathrm{Ca}$ count rate at the end rises to approximately 40,000 counts $\mathrm{s}^{-1}$ (Fig. 5b). The high $\mathrm{Ca}$ count rates show that the analytical volume contains a significant fraction of melilite. In the central portion of the profile, $\mathrm{Ca}$ counts are low and Ti counts high and relatively constant. These features are consequences of the highly penetrative nature of XANES, and this must be taken into account to properly interpret possible variations in Ti valence near the margins of the spinel grain. We give a brief overview of our approach to this problem here. Greater detail can be found in Appendix S3 of the supporting information.

In our XANES analyses, incoming photons are collimated into an approximately $2 \mu \mathrm{m}$ diameter beam as they strike the surface of the sample and they penetrate deeply into the solid substrate (the attenuation mean free path in spinel is $23 \mu \mathrm{m}$ at the Ti K edge). To understand how this affects the analysis, consider Fig. 6. Based on the square cross section of B4 (Fig. 5a), a plausible shape for the grain is that of an octahedron truncated by the thickness of the thin section, as shown schematically in Fig. 6. The entrance photon angle is $45^{\circ}$ relative to the surface of the section, as is the detected angle of the fluoresced $\mathrm{Ti}$ or Ca X-ray. At the beginning of the profile (trajectory A), the primary photon beam penetrates into spinel and, because of the $45^{\circ}$ incidence angle, the analyzed volume contains only spinel. Analytical volumes at the other end of the profile (trajectory B), however, include large amounts of melilite, even though the surface intersection of the photon beam is in spinel. As more analysis points near the end of the traverse sample significant amounts of surrounding material than do those at the beginning of the traverse, this leads to an asymmetric profile in $\mathrm{Ca}$ and $\mathrm{Ti}$ counts.

In addition to the subsurface geometry of spinel grains, boundary clinopyroxenes on surfaces of spinel grains included in melilite and anorthite (Paque et al. 2009) can also complicate the interpretation of XANES profiles, especially near crystal margins. To test for the presence of interference from boundary clinopyroxene, we modeled quantitatively the observed $\mathrm{Ti}$ and $\mathrm{Ca}$ count rate profiles for B4, assuming only fluorescent

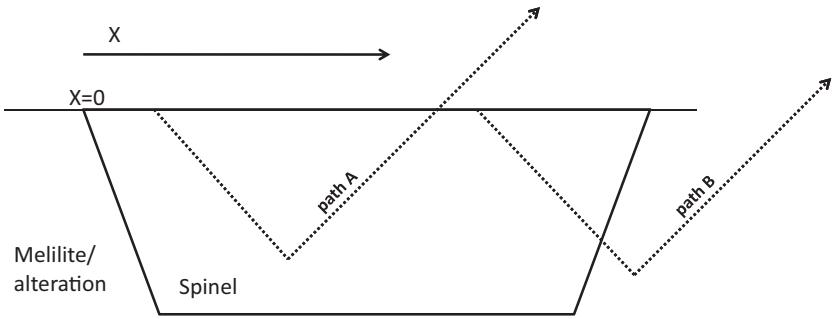

Fig. 6. Schematic diagram of the interaction of a synchrotron beam with a spinel grain in thin section surrounded by high$\mathrm{Ca}$, low-Ti phases, such as melilite or alteration products. The incoming photons and outgoing (detected) X-rays are oriented at a $45^{\circ}$ angle to the surface of the thin section. XANES traverses were generally taken so that photons for the first analysis point enter the spinel near the spinel-host boundary $(\mathrm{X}=0)$, but, because the path extends into spinel at depth, there may be very little contribution of the host phase to the X-rays exiting the sample at $45^{\circ}$. Thus, the early and midportions of such a XANES traverse (e.g., path A) would almost entirely sample spinel. As the photon entry point approaches the opposite end of the spinel grain, however, the path of the incoming photon samples both spinel and the surrounding host phase(s) (path B). For spinel in melilite, this portion of the profile is characterized by a drop-off in $\mathrm{Ti}$ and a corresponding rise in $\mathrm{Ca}$ as progressively greater amounts of the host melilite are sampled.

$\mathrm{X}$-rays from spinel, melilite, and alteration products. A good fit to the count rate profiles would argue against the presence of significant contributions from boundary clinopyroxene to the observed Ti count rates. Details of the modeling are described in Appendix S3 of the supporting information. Briefly, model profiles were calculated for an octahedral shape truncated by the base of the thin section (Fig. 6) and for an octahedron tilted $22.5^{\circ}$ counterclockwise relative to the direction of the profile. As shown in Appendix S3 (Figs. S3, S5, and S6), both models, especially the tilted octahedron, provide a reasonable, although not perfect, description of the observed profiles. Most importantly, both models somewhat overestimate the Ti count rate for the exiting part of the profile. If the models had seriously underestimated the $\mathrm{Ti}$ count rates, contributions from boundary clinopyroxenes would be indicated, but such contributions appear unnecessary (below we show examples where boundary clinopyroxenes are important contributors to the measured $\mathrm{Ti}$ counting rate). Thus, with the possible exception of the final two analyses (at 60 and $80 \mu \mathrm{m}$ ), observed Ti X-rays from the B4 profile come almost entirely from spinel in both models (Table S5 of the supporting information). The observed Ti valences can therefore be associated solely with spinel and we can conclude that the observed $\mathrm{Ti}^{+3}$ enrichments ( $T i$ valence decrease) at the edge of spinel $B 4$ are real and are not an analytical artifact. 
By combining XANES and electron probe data, which yield total $\mathrm{Ti}$ near the surface of the section, $\mathrm{Ti}^{+3}$ and $\mathrm{Ti}^{+4}$ zoning profiles in B4 spinel can be calculated (Fig. 5d). Relative to the grain interior, the B4 rims are enriched in $\mathrm{Ti}^{+3}$ by a factor of 3-4 and depleted in $\mathrm{Ti}^{+4}$ by about a factor of 2 . From the electron probe data, in terms of total $\mathrm{Ti}$ expressed as $\mathrm{TiO}_{2}{ }^{*}$, B4 has a $\mathrm{rim} /$ core $\mathrm{TiO}_{2}{ }^{*}$ ratio of about 1.1 (i.e., a slight increase in total Ti toward the rim).

Figures 7 and 8 show profiles for two spinel grains from TS34, A9 (mantle melilite host), and B2 (core melilite host), respectively. The entry portions of traverses for both grains show lower Ti counts, high $\mathrm{Ca}$ count rates, and low valence relative to inner points, consistent with zoning in the spinel toward rims with low Ti valence. In the A9 data (Fig. 7b), the final three analyses show a strong decrease in $\mathrm{Ti}$ count rate and increase in $\mathrm{Ca}$ count rate, as would be expected for contributions from melilite; there is, however, a spike in the Ti count rate at $85 \mu \mathrm{m}$. This spike and a similar increase in Ti count rate at the exiting part of the B2 count rate profile shown in Fig. $8 \mathrm{~b}$ indicate sampling of Ti-rich phases, and both are undoubtedly due to input from boundary clinopyroxenes (Paque et al. 2009). We selected profiles so that they would miss any boundary clinopyroxene visible in the plane of the section, but subsurface grains and, especially, films could not be completely avoided. The observed increase in $\mathrm{Ti}$ count rate apparent in Fig. $7 \mathrm{~b}$ can be accounted for by a 0.2 $0.3 \mu \mathrm{m}$ thick, subsurface clinopyroxene grain or film. The decrease in Ti valence for the points influenced by boundary clinopyroxene indicates that, qualitatively at least, these boundary clinopyroxenes are $\mathrm{Ti}^{+3}$-rich, consistent with $\mathrm{Ti}^{+3} / \mathrm{Ti}^{+4}$ ratios inferred from electron probe analyses of boundary clinopyroxenes adjacent to other spinel grains (Kuehner et al. 1989). Quantitative estimates of the $\mathrm{Ti}$ valence of boundary clinopyroxene based solely on the XANES measurements are not possible because the sampling volume of the XANES analysis is far greater than the volume of boundary clinopyroxene and the proportions of the sampled phases are not known.

Spinels enclosed in melilite have hosts with very low concentrations of $\mathrm{Ti}$, but, for spinel enclosed in clinopyroxene, $\mathrm{Ti}^{+3}$ and $\mathrm{Ti}^{+4}$ abundances in the host are far greater than in the spinel, so quantification of $\mathrm{Ti}$ valence in noncore regions of spinel inclusions in clinopyroxene requires explicitly accounting for clinopyroxene contributions to the XANES spectrum. Figure 9 shows $\mathrm{Ti}$ and $\mathrm{Ca}$ count rate (Fig. 9b) and $\mathrm{Ti}$ valence (Fig. 9c) profiles for a large spinel grain, B3, in clinopyroxene in TS34 (Fig. 9a). Raw valence determinations are shown in Fig. 9c, but these include contributions from both the clinopyroxene host and the
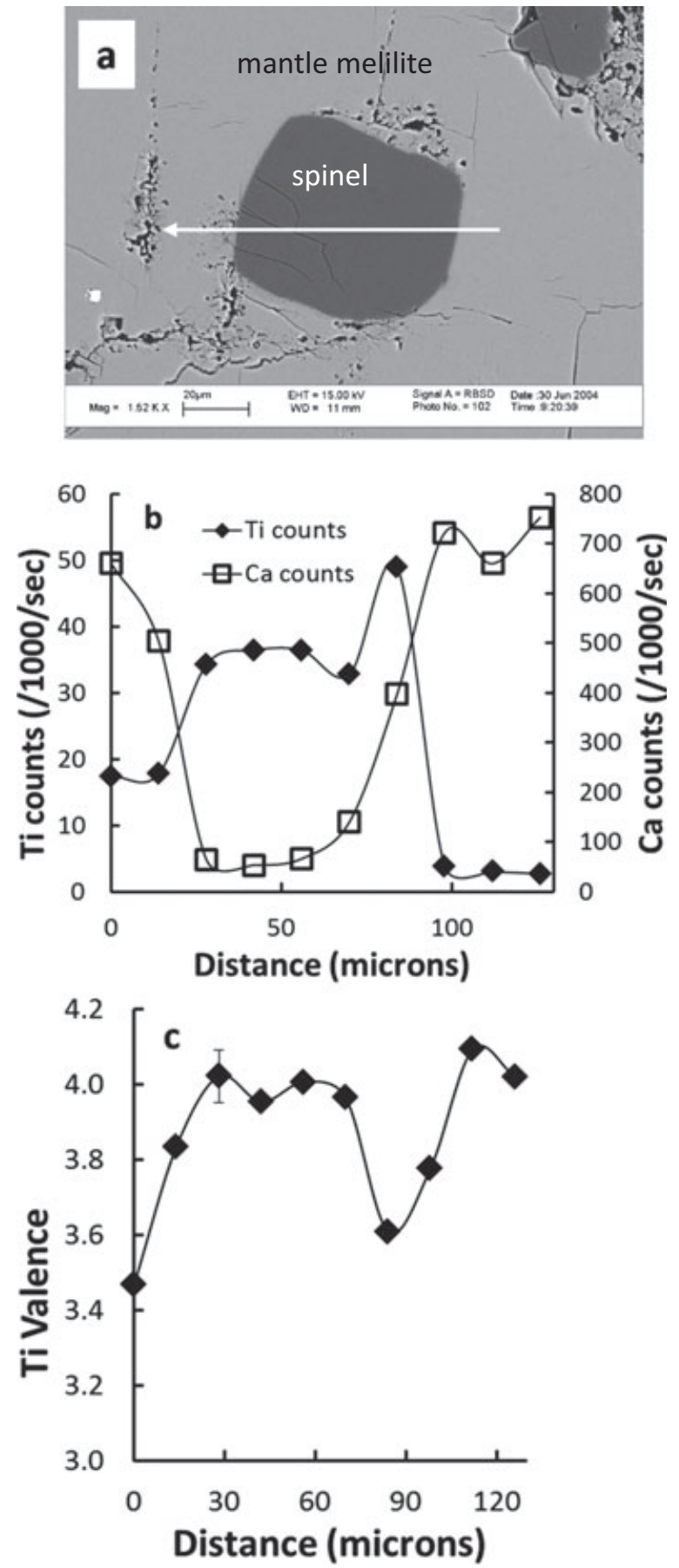

Fig. 7. Ti K XANES results for spinel grain A9, from the melilite mantle of Allende Type B1 inclusion TS34. a) BSE photomicrograph with direction and path of XANES traverse indicated by a white arrow. Scale bar is $20 \mu \mathrm{m}$. b) Ti and Ca count rates as a function of distance. c) $\mathrm{Ti}$ valence as a function of distance along the traverse. At the beginning and end of the traverse, $\mathrm{Ca}$ counts are high and $\mathrm{Ti}$ counts low, consistent with contamination by host melilite. There is, however, also a decrease in Ti valence around $85 \mu \mathrm{m}$ (panel c) that is accompanied by a spike in the Ti count rate (panel b). This probably reflects the presence of $\mathrm{Ti}^{+3}$ - rich boundary clinopyroxene at depth between spinel and host melilite. 

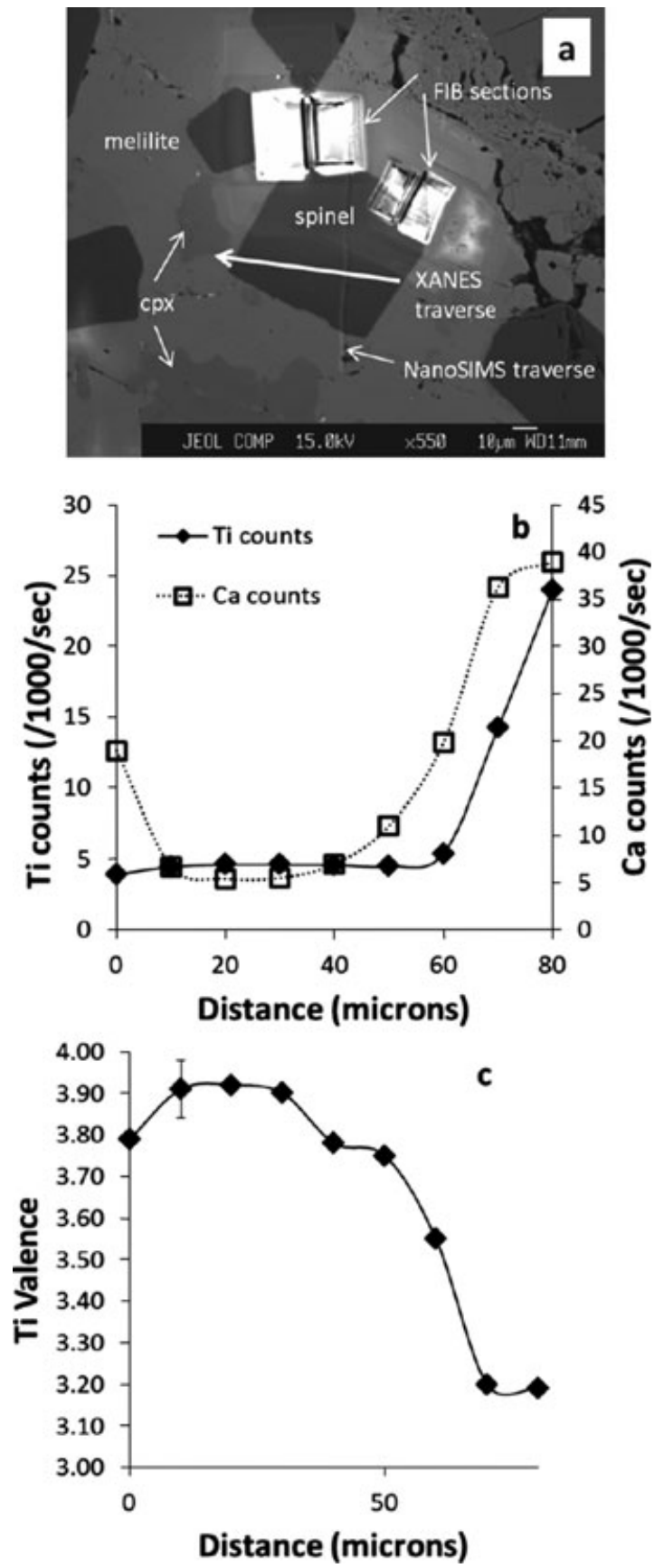

Fig. 8. Ti K XANES results for spinel grain $\mathrm{B} 2$ included in melilite from the core of Allende Type B1 inclusion TS34. a) BSE photomicrograph. The direction and path of the XANES traverse are indicated by the white arrow. The bright rectangular regions outline portions of the sample excavated to make FIB sections for a previous study (Paque et al. 2009). The linear feature roughly perpendicular to the XANES traverse is a trench produced by a NanoSIMS traverse (Paque et al. 2006). Scale bar is $10 \mu \mathrm{m}$. b) $\mathrm{Ti}$ and $\mathrm{Ca}$ count rate as a function of distance. c) Ti valence as a function of distance along the XANES traverse. As with spinel grain A9 (Fig. 7), the simultaneous decrease in $\mathrm{Ti}$ valence and increase in $\mathrm{Ti}$ count rate beyond approximately $50 \mu \mathrm{m}$ reflect the presence of clinopyroxene on or near the spinel grain boundary. included spinel, as indicated by the simultaneous count rate increases for both $\mathrm{Ca}$ and $\mathrm{Ti}$ (Fig. 9b).

In this case, we corrected for clinopyroxene spectral interferences by using a "full-spectrum" analysis. The measured average valences for Ti are based only on the portion of the XANES region of the spectrum from 4960 to $4980 \mathrm{eV}$ (Figs. 1 and 2). This portion of the spectrum is sensitive to Ti valence, but insensitive to what phase(s) are contributing to the signal. At higher energies, however, there are a pair of EXAFS peaks, at 4987 and $4998 \mathrm{eV}$ for clinopyroxene, and at slightly higher energies for spinel (Fig. 1). The EXAFS peaks are insensitive to $\mathrm{Ti}$ valence, but, where good reference spectra for endmember spinel and clinopyroxene are available from the same sample, the full spectrum from 4960 to $5050 \mathrm{eV}$ can be used to quantitatively define proportions of the two phases within the sampled volume.

The spinel and clinopyroxene spectra are sufficiently distinct (Fig. 1) that the proportions of the $\mathrm{Ti}$ signal deriving from the two phases can be determined using a least-squares, linear combination of endmember spectra over the energy range from 4960 to $5050 \mathrm{eV}$. The endmember spectra used were (1) the $80 \mu \mathrm{m}$ point from the B3 traverse (clinopyroxene) and (2) the $42 \mu \mathrm{m}$ point from the A9 traverse (spinel). For the other analysis points on Figs. 9b and 9c, the fractions of Ti counts coming from clinopyroxene and spinel were calculated from the full spectrum fit. Clinopyroxene contributions dominate; even at the center of the grain, $20-40 \%$ of the counts are from clinopyroxene. Given the proportions of spinel and clinopyroxene from decomposition of the EXAFS spectrum, the XANES spectra can be fit to a mixture of $\mathrm{Ti}^{+3}$ and $\mathrm{Ti}^{+4}$. Very good fits to the B3 XANES profile are obtained with mixtures of spinel having a $\mathrm{Ti}$ valence of 3.9-4.1 (essentially 4) and clinopyroxene with a valence of 3.05 (representing the B3 clinopyroxene host). The corrected valence profile for the spinel grain is shown in Fig. 9d. We find no evidence for any significant enrichments in $\mathrm{Ti}^{+3}$ at spinel edges; i.e., the data are compatible with spinel having uniformly high $\mathrm{Ti}$ valence $(\geq 3.9)$, although, given the errors in the correction, we cannot preclude $\mathrm{Ti}^{+3}$ edge enrichments of up to $20 \%$. The decomposition is imperfect in that a clinopyroxene valence of 3.05 is significantly less than is observed in electron probe measurements of $\mathrm{Ti}^{+3} / \mathrm{Ti}^{+4}$.

\section{Vanadium Valence in Spinel}

\section{$\checkmark$ Valence in CAls}

In terrestrial crystalline materials, $\mathrm{V}$ is generally trivalent or pentavalent. Based on XANES measurements, however, divalent $\mathrm{V}$ is common in samples formed under reducing conditions (IW or 

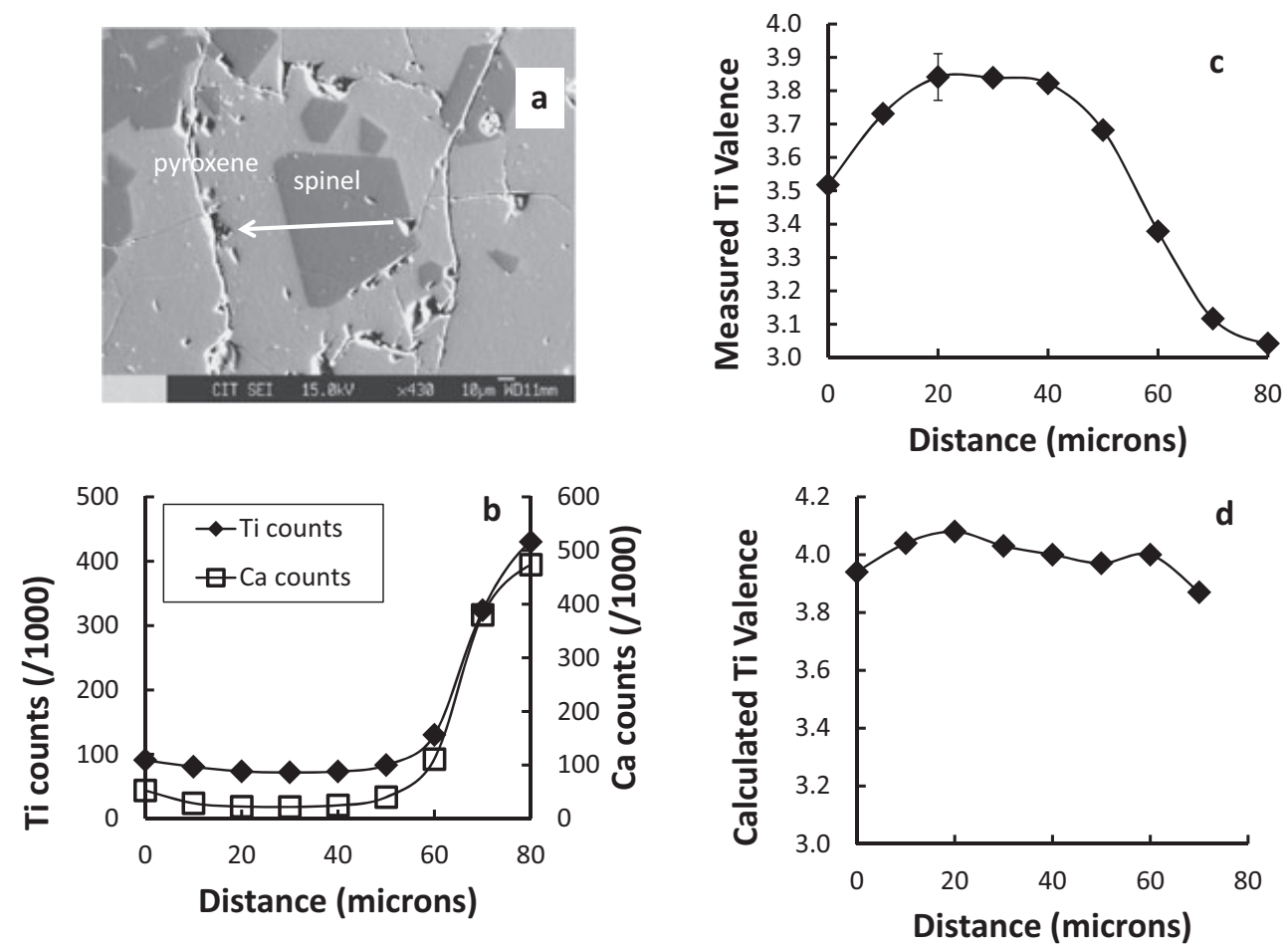

Fig. 9. Ti K XANES results for spinel grain B3 included in clinopyroxene from the core of Allende Type B1 inclusion TS34. a) BSE photomicrograph with direction and path of XANES traverse indicated by a white line and arrow. Scale bar is $10 \mu \mathrm{m}$. b) $\mathrm{Ti}$ and $\mathrm{Ca}$ count rate as a function of distance. c) Titanium valence as a function of distance. A representative error bar is shown. d) Calculated $\mathrm{Ti}$ valence in the spinel according to full-spectrum analyses, which were used to distinguish contributions from spinel and clinopyroxene. These corrected analyses are consistent with an unzoned grain containing pure $\mathrm{Ti}^{+4}$, although $\mathrm{Ti}^{+3}$ rim enrichments of roughly $20 \%$ cannot be ruled out.

below; Sutton and Newville 2005). Good XANES calibration data for $\mathrm{V}$ are available from a suite of endmember, stoichiometric V-spinels of different valence states (Righter et al. 2006). XANES V data are also available for clinopyroxene in several of the inclusions studied here, including TS34 (Simon et al. 2007). Moreover, concentrations and valences of $\mathrm{V}$ are similar in spinel and clinopyroxene, so clinopyroxene interference in a XANES spectrum of spinel is much less of a concern for $\mathrm{V}$ than it is for Ti.

Figure 10 and Table 5 summarize spinel $\mathrm{V}$ valence data. To have a common scale, data are plotted in Fig. 10 as a function of distance along the tracks of traverses, expressed as a percentage of the distance between the two spinel grain rims along the common length scale. Thus, an analysis from the core of a spinel grain would plot at $50 \%$. All of the spinel data are characterized by subequal amounts of $\mathrm{V}^{+2}$ and $\mathrm{V}^{+3}$, with valences ranging from 2.48 to 2.60 . We observed no significant difference in $\mathrm{V}$ valence between spinels enclosed in melilite and those enclosed in clinopyroxene. Thus, the uniform measured $\mathrm{V}$ valence for the B3 profile can be confidently ascribed to the spinel. The clinopyroxene host of $\mathrm{B} 3$ has a very similar $\mathrm{V}$ valence to the B3 spinel, and Simon et al. (2007) found mean V valences of $2.4 \pm 0.1$ and $2.50 \pm 0.02$ for two large clinopyroxene grains from TS34, consistent with a V valence of approximately 2.5 for both spinel and clinopyroxene in this inclusion.

\section{$\checkmark$ Valence for Synthetic Spinel}

A few reconnaissance measurements were made of the $\mathrm{V}$ valence in the cores of spinels in the $\mathrm{HC}$ experimental samples. The results are summarized in Table 2. HC13, synthesized in air, has a very high $\mathrm{V}$ valence $(4.83 \pm 0.05)$ dominated by $\mathrm{V}^{+5}$. The high proportion of $\mathrm{V}^{+5}$ in the $\mathrm{HC} 13$ sample is surprising as, even in air, a significant proportion of $\mathrm{V}^{+3}$ should be present, which should preferentially be incorporated into the spinel. However, the $\mathrm{HC} 13$ analysis was made on a large clump of sutured spinel grains and, possibly, sampled glass from grain boundaries, which had oxidized during quench. Spinel in the other two analyzed run products has $\mathrm{V}$ valences of approximately 2.6, basically the same as the TS34 spinels (Fig. 10). HC13 was crystallized during a dynamic crystallization experiment conducted at approximately IW and HC14 was crystallized at $\mathrm{CCO}$, more than seven orders of 


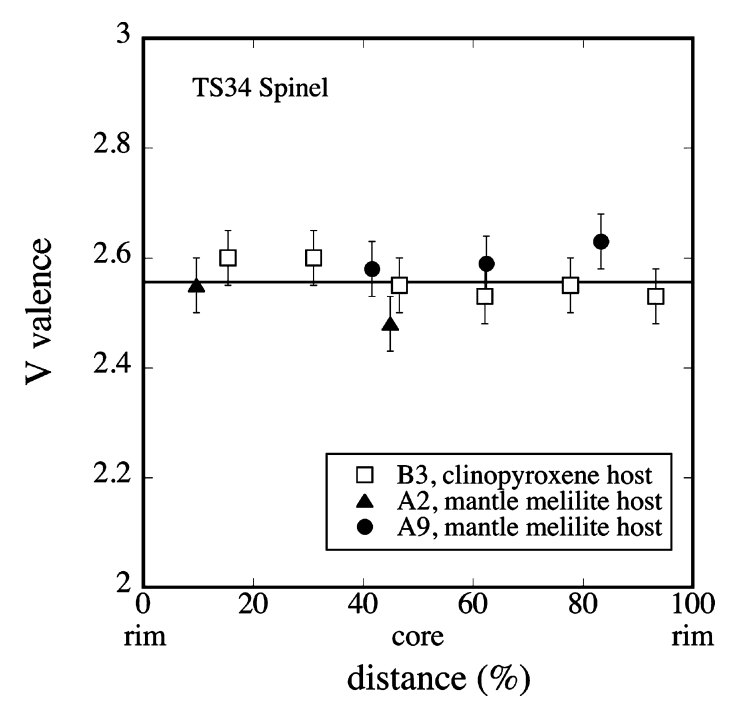

Fig. 10. XANES data for V valences of TS34 spinel, plotted as a function of percent distance from the spinel-host interface to facilitate comparison of data for different grains. A corerim pair (A2) and two traverses (A9, B3) are plotted. The average $\mathrm{V}$ valence (2.56) for $\mathrm{B} 3$ analyses is shown as a horizontal line as a visual reference. Spinel inclusions in mantle melilite (A2, A9) and core clinopyroxene (B3) have approximately equal amounts of $\mathrm{V}^{+2}$ and $\mathrm{V}^{+3}$.

Table 5. Vanadium results from XANES analyses of spinel in Allende TS34, a type B CAI.

\begin{tabular}{llcl}
\hline Spinel \# & Spinel host & Spinel V valence & $1 \sigma$ \\
\hline A9 & mantle mel & 2.58 & 0.05 \\
A9 & mantle mel & 2.59 & 0.05 \\
A9 & mantle mel & 2.63 & 0.05 \\
B3 & cpx & 2.60 & 0.05 \\
B3 & cpx & 2.60 & 0.05 \\
B3 & cpx & 2.55 & 0.05 \\
B3 & cpx & 2.53 & 0.05 \\
B3 & cpx & 2.55 & 0.05 \\
B3 & cpx & 2.53 & 0.05 \\
A2 & mantle mel & 2.55 & 0.05 \\
A2 & mantle mel & 2.48 & 0.05 \\
\hline
\end{tabular}

magnitude more reducing. As noted above in the context of $\mathrm{Ti}$ valence, there is uncertainty as to the temperature and, therefore, $f \mathrm{O}_{2}$ at the time the analyzed spinel crystallized in $\mathrm{CCO}$ experiments, but, for $\mathrm{HC} 14$ (CCO), this effect is small. The virtually identical $\mathrm{V}$ valences in runs at $\mathrm{CCO}$ and IW also agree with those measured in spinels (Fig. 10) and clinopyroxene (Simon et al. 2007; this study) in CAIs. This may hint at ordering of $\mathrm{V}^{+2}$ $\mathrm{V}^{+3}$ couples within clinopyroxene and spinel, perhaps under subsolidus conditions, with stabilization at a roughly 50:50 mixture, e.g., via an intervalence Ti-V equilibrium as suggested by Simon et al. (2007). Regardless of their origin, $\mathrm{V}$ valences appear insensitive to $f \mathrm{O}_{2}$ for conditions more reducing than IW.

\section{SIMS O and Mg Isotopic Analyses of Spinel from TS34}

We determined the oxygen and $\mathrm{Mg}$ isotopic compositions of six large spinel grains from TS34 for which XANES measurements were also made. A spotby-spot display of the $\mathrm{O}$ isotope data is given in Appendix S4 of the supporting information together with SEM images of the analyzed spots and spot-byspot data for $\delta^{26} \mathrm{Mg}_{\text {excess }}$ and $\Delta^{25} \mathrm{Mg}$. The oxygen compositions are ${ }^{16} \mathrm{O}$-rich, as expected for spinel found in refractory inclusions; no anomalous compositions were found. There is a significant spread in $\delta^{18} \mathrm{O}$ along the CCAM line ranging from -39 to $-50 \%$, slightly wider than the range, -48 to $-52 \%$, of ion probe analyses of spinel in this sample obtained by Connolly et al. (2003).

Table 6 summarizes SIMS $\mathrm{Mg}$ isotopic data for spinels in TS34. We analyzed six spinel grains with duplicate measurements on four of them. Analysis positions are shown in Appendix S4 of the supporting information. Excess ${ }^{26} \mathrm{Mg}$ due to ${ }^{26} \mathrm{Al}$ decay, $\delta^{26} \mathrm{Mg}_{\text {excess }}$, and enhancements in $\left({ }^{25} \mathrm{Mg} /{ }^{24} \mathrm{Mg}\right), \Delta^{25} \mathrm{Mg}$, are observed. An isochron plot of $\delta^{26} \mathrm{Mg}_{\text {excess }}$ versus ${ }^{27} \mathrm{Al} /{ }^{24} \mathrm{Mg}$ (Appendix S4 of the supporting information) shows that the spinel $\delta^{26} \mathrm{Mg}_{\text {excess }}$ data are compatible with ${ }^{26} \mathrm{Al} /{ }^{27} \mathrm{Al}=5.5 \pm 0.5 \times 10^{-5}$, the "canonical" value. Enhancements in ${ }^{25} \mathrm{Mg} /{ }^{24} \mathrm{Mg}$ (positive values of $\Delta^{25} \mathrm{Mg}$ ) are well documented in types $\mathrm{A}$ and $\mathrm{B}$ CAIs and are generally thought to reflect the evaporative loss of $\mathrm{Mg}$ from the melt in partially molten CAIs, with concurrently or subsequently crystallizing phases inheriting these enhancements from the liquid (e.g., Richter et al. 2007; Grossman et al. 2008b).

The present study represents the most complete data set for $\Delta^{25} \mathrm{Mg}$ thus far obtained for spinel from a single CAI. Figure $11 \mathrm{a}$ shows the $\Delta^{25} \mathrm{Mg}$ data on a point-by-point basis for spinel and, for three grains, for adjacent melilite. There is evidence of both inter- and intragrain variations in spinel at the permil level exceeding the $2 \sigma$ analytical errors, and, for mantle melilite (A9 and A2), there are significant differences between observed isotopic compositions of the spinel and host melilite. We focus first, however, on the mean $\Delta^{25} \mathrm{Mg}$ values for spinel, $4.25 \pm 0.18 \%$ (error is the $2 \sigma$ mean of the measured spot $\Delta^{25} \mathrm{Mg}$ ) and melilite $(4.09 \pm 0.12 \%)$. After correcting for the different standards used for instrumental mass fractionation, the TS34 whole rock $\Delta^{25} \mathrm{Mg}$ from Grossman et al. (2008a, 2008b) agrees within error with our melilite values.

Figure $11 \mathrm{~b}$ shows $\mathrm{TiO}_{2} *$ in spinel as a function of $\Delta^{25} \mathrm{Mg}$. The lowest $\Delta^{25} \mathrm{Mg}$ values occur in spinel hosted by melilite and anorthite in the inclusion core, and the highest values are in spinel enclosed in mantle melilite and high- $\mathrm{TiO}_{2} *$ clinopyroxene. 
Table 6. Mg isotopic analyses of TS34 spinel.

\begin{tabular}{|c|c|c|c|c|c|c|c|}
\hline 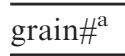 & spot\# & $\delta^{26} \mathrm{Mg}_{\text {excess }} \mathrm{b}$ & $2 \sigma$ & ${ }^{27} \mathrm{Al} /{ }^{24} \mathrm{Mg}^{\mathrm{c}}$ & $2 \sigma$ & $\Delta^{25} \mathrm{Mg}^{\mathrm{d}}$ & $2 \sigma$ \\
\hline B3 & \#19 & 0.93 & 0.14 & 2.439 & 0.002 & 4.45 & 0.14 \\
\hline B3 & $\# 20$ & 0.98 & 0.13 & 2.465 & 0.002 & 4.34 & 0.14 \\
\hline A9 & \#21 & 0.94 & 0.16 & 2.465 & 0.002 & 4.37 & 0.15 \\
\hline A9 & \#22 & 1.06 & 0.23 & 2.470 & 0.002 & 4.41 & 0.16 \\
\hline B4 & \#23 & 1.08 & 0.21 & 2.510 & 0.002 & 3.81 & 0.16 \\
\hline B4 & \#24 & 0.96 & 0.15 & 2.539 & 0.002 & 4.38 & 0.15 \\
\hline B2 & $\# 25$ & 1.04 & 0.23 & 2.513 & 0.002 & 3.95 & 0.16 \\
\hline B2 & \#26 & 0.93 & 0.20 & 2.533 & 0.002 & 4.26 & 0.15 \\
\hline F2 & \#27 & 1.11 & 0.20 & 2.556 & 0.002 & 3.85 & 0.15 \\
\hline A2 & $\# 29$ & 0.97 & 0.12 & 2.490 & 0.002 & 4.72 & 0.14 \\
\hline
\end{tabular}

${ }^{\mathrm{a}}$ See Table 3 for description of spinel grains and their host phases and references to more extensive descriptions of the host CAI, TS34.

${ }^{\mathrm{b}} \delta^{26} \mathrm{Mg}_{\text {excess }}=\left(\left[\left({ }^{26} \mathrm{Mg} /{ }^{24} \mathrm{Mg}\right)_{\text {meas }} /\left({ }^{26} \mathrm{Mg} /{ }^{24} \mathrm{Mg}\right)_{\text {corr }}\right]-1\right) \times 1000$, where $\left({ }^{26} \mathrm{Mg} /{ }^{24} \mathrm{Mg}\right)_{\text {corr }}=\left({ }^{26} \mathrm{Mg} /{ }^{24} \mathrm{Mg}\right)_{\text {meas }}\left(1+2 \times \Delta^{25} \mathrm{Mg}\right)$. The abbreviation "meas" refers to a measured value and "corr" refers to a value corrected for mass fractionation.

"SIMS analyses.

${ }^{\mathrm{d}} \Delta^{25} \mathrm{Mg}=\left(\left[\left({ }^{25} \mathrm{Mg} /{ }^{24} \mathrm{Mg}\right)_{\text {meas }} /\left({ }^{25} \mathrm{Mg} /{ }^{24} \mathrm{Mg}\right)_{\text {ref }}\right]-1\right) \times 1000$, where $\left({ }^{25} \mathrm{Mg} /{ }^{24} \mathrm{Mg}\right)_{\text {ref }}=0.12663$ (Catanzaro et al. 1966).

Four grains were analyzed twice. For two of these (A9 and B3), $\Delta^{25} \mathrm{Mg}$ values overlap at $1 \sigma$ (Fig. 11a). Differences are larger for spinels B2 and B4, enclosed in melilite in the inclusion core. For B2, the high- $\Delta^{25} \mathrm{Mg}$ analysis is from the rim and the low- $\Delta^{25} \mathrm{Mg}$ analysis is from the interior of the crystal, which hints at zoning from lower to higher $\Delta^{25} \mathrm{Mg}$. This would be consistent with crystallization of spinel from a residual liquid during volatilization, with insufficient time at elevated temperatures for diffusive re-equilibration in spinel. Both B4 analyses are from the outer portions of the crystal and we cannot distinguish contributions from inner and outer regions of the crystal.

Although differences are small, it is also notable that $\Delta^{25} \mathrm{Mg}$ in mantle melilite is lower than in nearby spinels (A2 and A9), consistent with a lack of equilibration between these two phases (Fig. 11a). As $\mathrm{Mg}$ self-diffusion is considerably faster than chemical diffusion of high-valence cations like $\mathrm{Ti}$ (e.g., Van Orman and Crispin 2010), the lack of homogenization of $\mathrm{Ti}$ valence and $\mathrm{Ti}$ concentration within spinel is not surprising, given the lack of equilibration of $\mathrm{Mg}$ isotopes. Overall, the $\mathrm{Mg}$ isotopic data for spinel and melilite are consistent with the conceptual framework championed by Grossman et al. (2002) or Richter et al. $(2002,2007)$ in which volatilization leads to chemical and isotopic zoning in the partially molten CAIs. Phases crystallizing from such liquids would be expected to incorporate the $\mathrm{Mg}$ isotopic composition of the local melt, but this composition might depend on spatial position within the inclusion and the thermal history of the inclusion.
TS34 is typical of CAIs in having much heavier O isotopic compositions in melilite than observed for spinel (Connolly et al. 2003). We accept the conventional interpretation (e.g., Clayton 2005) that substantial postcrystallization $\mathrm{O}$ isotope exchange of melilite with an isotopically heavy $\mathrm{O}$ reservoir (nebular gas) has occurred, but that spinel was much less affected. It is conceivable that the small differences in $\Delta^{25} \mathrm{Mg}$ between melilite and spinel (Fig. 11a) were produced during the $\mathrm{O}$ isotope exchange.

\section{DISCUSSION}

\section{Lessons from the CAIs}

\section{Titanium in Cores of Spinels in TS34 Is Predominantly $\mathrm{Ti}^{+4}$}

There are multiple lines of evidence to suggest that cores of spinel in TS34 were not produced under the same reducing conditions that generated the $\mathrm{Ti}^{+3}$-rich clinopyroxenes found in the same inclusion. Analyses of 11 spinels from TS34 show a predominance of $\mathrm{Ti}^{+4}$ (Figs. 4a, 5, and 7-9), even though some of these crystals are in contact with $\mathrm{Ti}^{+3}$-rich clinopyroxene. Considering only data from grain cores, none of the measured valences are less than 3.68 and all but two are greater than 3.8. (Typical $1 \sigma$ errors on the valence are 0.05-0.07 based on XANES spectral fits, Table 3.) Based on the relationship between $\mathrm{Ti}^{+3} / \mathrm{Ti}^{+4}$ derived from our experiments (e.g., Fig. 3b), spinel that crystallized from liquids that equilibrated with the same vapor that equilibrated with host clinopyroxenes at the 

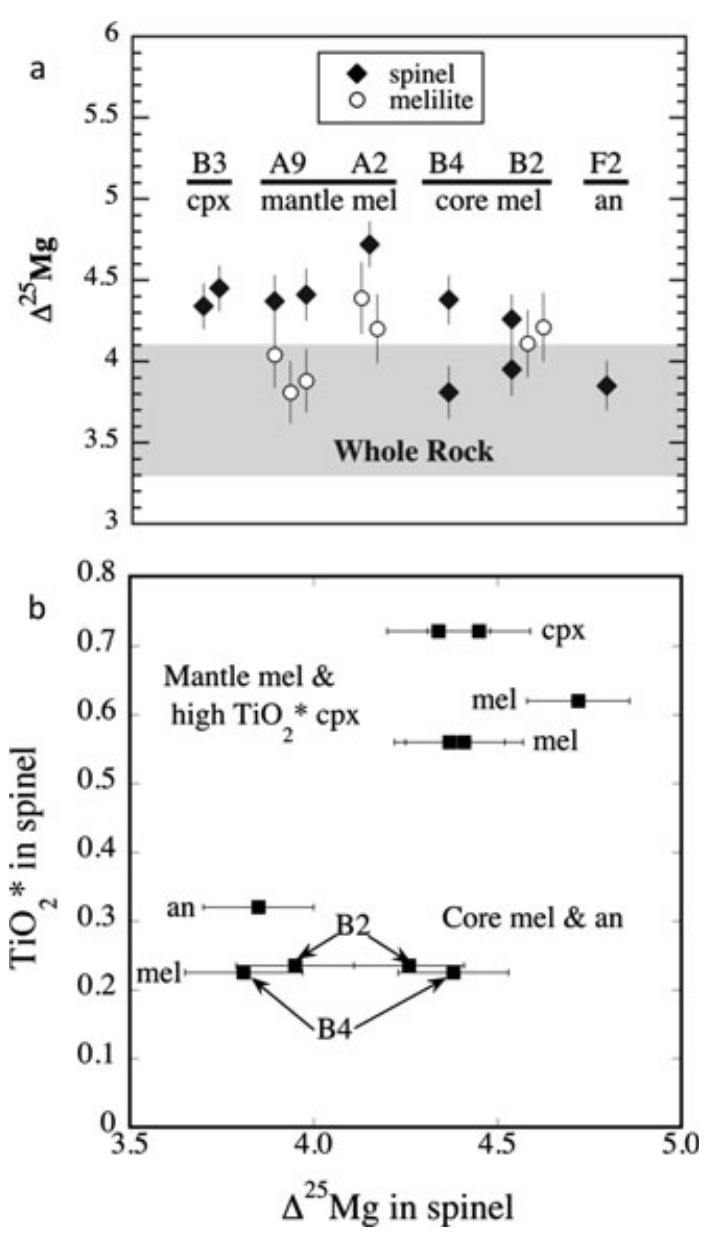

Fig. 11. a) SIMS measurements of mass-dependent $\mathrm{Mg}$ isotopic fractionation (Table 6) in large spinel grains from TS34. Grains are inclusions in clinopyroxene (B3), mantle melilite (A2, A9), core melilite (B2, B4), and anorthite (F2). Four of the six grains were large enough for replicate analyses and, with the notable exception of B4, these agree within $2 \sigma$. There may be real variations in fractionation up to several tenths of a permil within individual spinel crystals and up to $1 \%$ between different crystals. For three spinels, analyses were made in adjacent melilite. For the mantle melilite spinels A9 and $\mathrm{A} 2$, the melilite is about $0.5 \%$ lower than spinel. No difference is observed between B2 spinel and melilite in the core of TS34. The whole rock analysis of Grossman et al. (2008b) agrees with all but one of the melilite analyses within $2 \sigma$. b) $\mathrm{TiO}_{2}{ }^{*}$ versus $\Delta^{25} \mathrm{Mg}$ in spinel. Analyses for B2 and B4 are indicated on the panel. Abbreviations as in Fig. 4a.

same or lower temperatures, would be $\mathrm{Ti}^{+3}$-rich, with even lower valences than coexisting clinopyroxene (Fig. 3b). The observed $\mathrm{Ti}$ valences in the spinel cores are invariably much higher than for clinopyroxene. We emphasize two important specific cases: (1) surprisingly, cores of TS34 spinel inclusions in clinopyroxene are $\mathrm{Ti}^{+4}$-rich, even though they are located in $\mathrm{Ti}^{+3}$-rich clinopyroxene hosts and (2) cores of spinels from the melilite mantle of TS34 are characterized by high Ti valence; these spinels crystallized prior to the appearance of clinopyroxene and should have had lower $\mathrm{Ti}$ valence if they crystallized from $\mathrm{a} \mathrm{Ti}^{+3}$-rich melt under highly reducing (i.e., solar) conditions.

\section{Overview of Models}

The presence of $\mathrm{Ti}^{+4}$-enriched spinel cores is consistent with the idea that the spinels equilibrated under highly oxidizing conditions, which might, for example, occur through oxidation during volatilization (see model I below).

A high $\mathrm{Ti}$ valence in spinel does not, however, necessarily imply highly oxidizing conditions in the ambient environment. Based on the spinel/liquid partition coefficient for $\mathrm{Ti}^{+4}$ of 0.04 reported by Connolly and Burnett (2003), the concentrations of $\mathrm{Ti}$ in spinel are generally much higher than can be accounted for by crystallization of a homogeneous, near-liquidus CAI-like melt. This effect can be seen in Fig. 12, in which the gray field encloses all of the core analyses of spinel from TS34. Also shown are isopleths of $\mathrm{TiO}_{2}$ and $\mathrm{Ti}_{2} \mathrm{O}_{3}$ in a coexisting melt, computed assuming that the spinel/liquid partition coefficients for $\mathrm{Ti}^{+4}$ and $\mathrm{Ti}^{+3}$ are 0.04 and 0.20 , respectively, following Connolly and Burnett (2003). (For consistency with the use of $\mathrm{TiO}_{2}{ }^{*}$ on the $\mathrm{x}$ axis in Fig. 12, $\mathrm{Ti}_{2} \mathrm{O}_{3}$ contents have been calculated as $\mathrm{TiO}_{2}$.) Melts in equilibrium with spinel cores in $\mathrm{TS} 34$ would be very $\mathrm{TiO}_{2}$-rich (6$16 \mathrm{wt} \%)$. As bulk Type $\mathrm{B}$ inclusions contain approximately $1 \mathrm{wt} \% \mathrm{TiO}_{2}{ }^{*}$ and as most spinel would have formed at low degrees of fractional crystallization (spinel is the liquidus phase), the observed $\mathrm{Ti}^{+4}$ contents of these spinels require very large enhancements in the $\mathrm{TiO}_{2}$ content of the local melt. Highly oxidizing conditions at near-liquidus temperatures would have led to high Ti valence in spinel, but not to high Ti concentrations. For example, Fig. 12 shows that, for a spinel with a $\mathrm{Ti}$ valence of 3.8 and $0.25 \% \mathrm{TiO}_{2}{ }^{*}$, a $\mathrm{TiO}_{2}$ concentration of about $5 \%$ is required in the liquid. Nor can one simply appeal to Ti enrichments in the outer portions of the inclusion relative to the interior prior to melting, as suggested by Kennedy et al. (1997), because local $\mathrm{Ti}$ concentrations would have to be enhanced relative to the bulk composition by factors of several or more everywhere in the inclusion. There are not enough $\mathrm{Ti}$ atoms to go around.

Based on the above analysis, $\mathrm{Ti}$ valence and concentration in the cores of spinels from TS34 cannot be accounted for through simple fractional crystallization of a homogeneous melt or of a droplet with radial variations in Ti concentrations, regardless of the selected oxygen fugacities.

We have considered two models in detail: (I) Crystallization of spinel under oxidizing conditions 


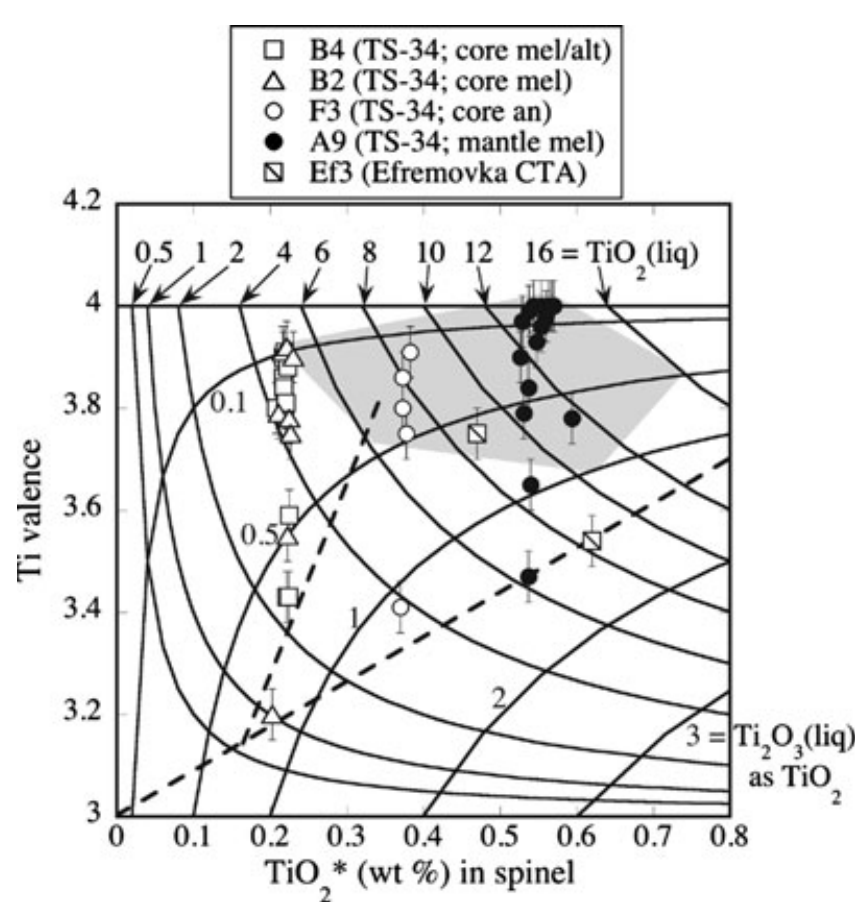

Fig. 12. Ti valence as a function of $\mathrm{wt}_{\mathrm{t}} \% \mathrm{TiO}_{2} *$ in spinel for traverses of spinel grains (B4, B2, F3, A9) in TS34 that are not bounded by clinopyroxene, using analyses that are consistent with there being no boundary clinopyroxenes within the analyzed volumes. Also shown are two analyses of spinel cores taken from the CTA Ef3 (cf. Fig. 4c). The lower of the two dashed lines bounds the meteoritic data. The upper dashed line, the type B trend for spinels that are not in TS34, and the gray region outlining TS34 data are taken from Fig. 4a. The panel is contoured in $\mathrm{wt}^{\mathrm{O}} \% \mathrm{TiO}_{2}$ and trivalent $\mathrm{Ti}$ calculated as $\mathrm{TiO}_{2}$ * for melts coexisting with spinel, assuming spinel/liquid partition coefficients for $\mathrm{Ti}^{+4}$ and $\mathrm{Ti}^{+3}$ of 0.04 and 0.2 , respectively.

produced by low-pressure evaporation. This model explains the high- $\mathrm{Ti}^{+4}$ cores and $\mathrm{Mg}$ isotope data naturally. However, as indicated above, there is serious difficulty in explaining the high $\mathrm{TiO}_{2}{ }^{*}$ contents. (II) Relict spinel-perovskite interactions. These can explain the high core valences and high $\mathrm{TiO}_{2}{ }^{*}$; however, there is possible difficulty explaining the $\mathrm{Mg}$ isotope data.

Other models are possible. For example, the primary melting event for igneous CAIs is widely believed to involve heating of refractory solid precursors. If the heating was rapid, the initial liquid could be out of equilibrium with prevailing nebular conditions. The redox conditions of this disequilibrium liquid are not predictable, but if alteration had already occurred in the precursor material, redox conditions in the liquid would initially be oxidizing, eventually becoming more reducing if equilibrium with more typical nebular reducing conditions was established. Spinel is the liquidus phase and, if it crystallized rapidly, it could acquire predominantly $\mathrm{Ti}^{+4}$. Rapid growth of spinel could also produce higher $\mathrm{Ti}$ concentrations than predicted from partitioning, but strong $\mathrm{Ti}$ zoning and anomalously high $\mathrm{Ca}$ concentrations in spinel would then be expected and these are not observed in the large spinels in TS34 (Connolly et al. 2003). The probability of CAI material, once altered, returning to nebular reducing conditions may be low, but this may not be necessary. Cooling to lower temperature under typical nebular reducing conditions may produce more O-rich secondary phases than the primary CAI phases. Thus, remelting could produce a transient oxidizing environment within the CAI, even though the overall nebular conditions were typical.

\section{Model-Independent Conclusions}

Before detailed discussion of models, we need to incorporate the lessons from the $\mathrm{Ti}^{+3}$-rich spinel rims in TS34, as these are readily accounted for by both models. We also need to integrate the data on spinel cores from CAIs other than TS34.

\section{Rims on Spinel in TS34}

To this point, we have concentrated on the core regions of spinel grains in TS34 because they are large and provide clear evidence for disequilibria with respect to the highly reducing conditions indicated by the clinopyroxenes in TS34. For spinels enclosed in melilite, anorthite, or alteration products, we can unambiguously determine $\mathrm{Ti}$ valence in rim regions, provided that there are no boundary clinopyroxenes in the analyzed volume. These crystals invariably show sharp decreases in $\mathrm{Ti}$ valence toward their rims (e.g., Fig. 5). Rims of spinels in TS34 appear to have crystallized/reequilibrated in a reducing environment, potentially consistent with crystallization in the same event that produced the low-valence clinopyroxene in that inclusion. In contrast, the spinel grain cores are inconsistent with crystallization under those same conditions.

In Fig. 12, we show data points for $\mathrm{Ti}$ valence in spinel as a function of $\mathrm{TiO}_{2}{ }^{*}$ from traverses across spinels in TS34 hosted by melilite, anorthite, and/or alteration products (e.g., Figs. 5, 7, and 8) for which the analyzed volumes are free of contamination from boundary clinopyroxenes. For each grain, data extend from high-valence cores to lower-valence rims. Without allowing for the actual subsurface grain shape, which is not known in detail, even analyses from the rim regions of a spinel grain may sample $\mathrm{Ti}^{+4}$-rich spinel from deeper regions within the analyzed volume. Figure 6 shows the special case in which grain diameter decreases 
with depth; it could just as easily increase. Thus, the lowest $\mathrm{Ti}$ valence point measured for each grain should be regarded as an upper limit. For A9 (Fig. 7), a crystal from the mantle of TS34, the inferred melt composition for the analysis with the lowest $\mathrm{Ti}$ valence is approximately $6 \mathrm{wt} \% \mathrm{TiO}_{2}$ and approximately $1.5 \mathrm{wt} \%$ trivalent $\mathrm{Ti}$ computed as $\mathrm{TiO}_{2}$, still much higher than bulk concentrations. Because clinopyroxene crystallization strongly affects $\mathrm{TiO}_{2} *$ in the melt, data for spinels from the inclusion core are difficult to interpret.

\section{Spinels from CAls Other than TS34}

Compositions of analyzed spinel in type B inclusions other than TS34 lie along the upper dashed line segment shown in Fig. 12 (data shown in Fig. 4a). At the lower end of the line, inferred Ti concentrations in the melt approach the bulk Ti contents of type B inclusions, especially given uncertainties in the temperature dependence of $\mathrm{Ti}^{+3} / \mathrm{Ti}^{+4}$ in the melt and the assumed constant values for the spinel/liquid partition coefficients. For example, if the partition coefficient for $\mathrm{Ti}^{+4}$ were 0.08 instead of 0.04 , the $0.5 \mathrm{wt} \%$ isopleth would plot where the $1 \mathrm{wt} \%$ isopleth is on Fig. 12, and inferred $\mathrm{TiO}_{2}{ }^{*}$ contents of the melt for the spinels with the lowest $\mathrm{Ti}$ valence would be approximately $1 \mathrm{wt} \%$.

The strong linearity in $\mathrm{Ti}$ valence- $\mathrm{TiO}_{2}{ }^{*}$ plots for spinel from most type B inclusions (e.g., Fig. 4a) suggests that, in general, the type B inclusions analyzed were subjected to similar conditions, so that the spinels were initially $\mathrm{Ti}^{+4}$-enriched, but the small spinel crystals, relative to those of TS34, yielded smaller amounts of $\mathrm{Ti}^{+4}$-enriched cores to be sampled. Among type B inclusions, TS34 appears to be unique only because the large spinel grains enabled the $\mathrm{Ti}^{+4}$-rich cores to survive lower temperature exposure to reducing conditions prior to and during clinopyroxene crystallization. The interpretation that the spinels with low Ti valence have re-equilibrated does not explain the linear trend in Fig. 4a; however, one variation of the relict spinel model (see scenario E, below) may explain the Fig. 4a trend.

\section{Common Ground among Models}

\section{There Is Time for Conditions to Change}

Both the relict spinel-perovskite and low-pressure evaporation models require transient processes in the initial stages of crystallization. The remarkable differences in apparent redox conditions recorded between spinel cores and clinopyroxene in TS34 seem more plausible when the large differences in appearance temperatures of spinel and clinopyroxene are considered. Figure 13 shows crystallization sequences

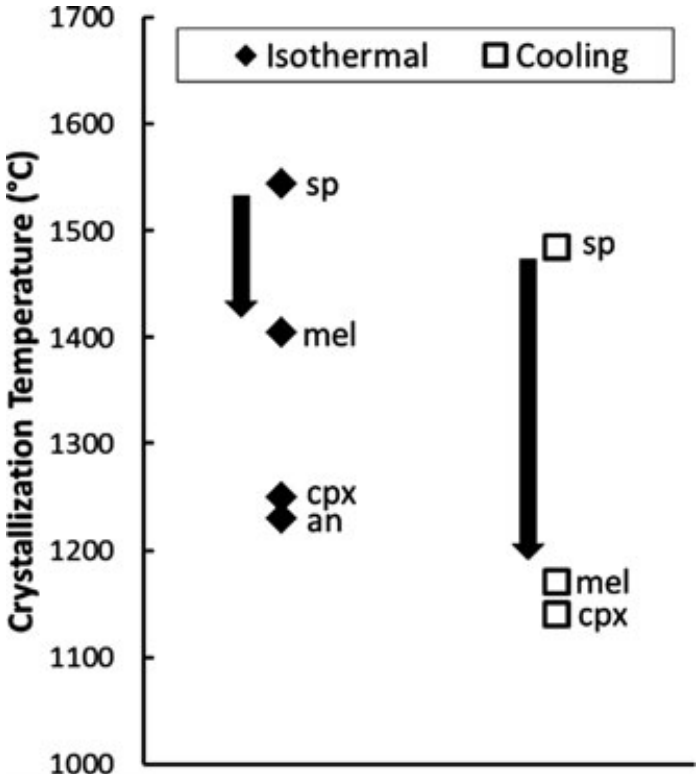

Fig. 13. Summary of experimentally determined crystallization sequences for an average type B bulk composition (Stolper 1982; Stolper and Paque 1986). Each symbol marks the appearance of a new phase with decreasing temperature, with the new phase indicated adjacent to the initial appearance temperature. The figure is quantitative for our isothermal and dynamic crystallization $\left(10^{\circ} / \mathrm{h}\right.$ starting from above the liquidus) experiments, but can also be viewed as a schematic representation of crystallization sequences for a broad range of type Bs, including TS34. Note, in particular, the delayed nucleation of silicates in the dynamic crystallization experiment, which leads to an expanded temperature interval for spinel-only crystallization. The arrows represent the temperature interval of spinel-only crystallization.

for a liquid of type B CAI composition from isothermal experiments (Stolper 1982) and for controlled cooling experiments $\left(10^{\circ} \mathrm{C} \mathrm{h}^{-1}\right.$; Stolper and Paque 1986). The difference between the spinel + liquid stability field and clinopyroxene appearance temperatures in the isothermal experiments is large, approximately $180{ }^{\circ} \mathrm{C}$, and the gap is even larger (almost $300^{\circ} \mathrm{C}$ ) under controlled cooling conditions because of supercooling and delayed nucleation. Cooling to below the spinel + liquid stability field at approximately $10{ }^{\circ} \mathrm{C} \mathrm{h}^{-1}$ (MacPherson et al. 1984) would allow approximately 1 day for lower oxygen fugacity conditions to be established (e.g., solar conditions; Grossman et al. 2008a) and for the valence of $\mathrm{Ti}$ in the melt to homogenize prior to crystallization of clinopyroxene, and thus be reflected in the $\mathrm{Ti}$ valence of the clinopyroxene.

\section{Relict Spinel-Perovskite Model}

There are several lines of evidence to suggest that maximum temperatures reached by type $\mathrm{B}$ inclusions 
did not exceed the liquidus (e.g., Stolper and Paque 1986; Richter et al. 2007). If the maximum temperature of an igneous CAI was in the relatively broad spinel + liquid field (Fig. 13), spinel formed in any precursor environment will be stable and, depending on details of the thermal history, might survive as a relict grain. Relict spinels have been suggested in many previous studies (e.g., Goswami et al. 1994; Connolly et al. 2003). Relict spinel + perovskite associations have been proposed to account for anomalous spinel boundary clinopyroxenes in type B1 CAIs (Paque et al. 2009). Equilibration of perovskite with spinel may have generated spinels with high proportions of $\mathrm{Ti}^{+4}$ without the intervention of an anomalously oxidizing ambient medium. Variations of this model based on spinelperovskite interaction must assume that the possible (probable?) presence of an overall reducing environment did not significantly disrupt the transfer of $\mathrm{Ti}^{+4}$ from perovskite to spinel. Spinel-perovskite associations are common petrographic features of type A CAIs, so the incorporation of perovskite-decorated spinel into a later-formed type B inclusion is plausible. Rubin (2012) proposed that type B CAIs were formed from reactions of older compact type A's with forsterite; this has a qualitative commonality with our relict spinel-perovskite model, but our data do not require accepting the other specific features of the Rubin model. Our use of perovskite in the following discussion is for simplicity; perovskite could be replaced by other $\mathrm{Ti}^{+4}$-rich phases such as panguite (Ma et al. 2012) with the basic interpretations unchanged.

If most of the $\mathrm{Ti}^{+4}$-enriched spinel is relict relative to the melting that produced the melilite mantle in TS34, then the $\Delta^{25} \mathrm{Mg}$ in these grains should reflect that of the pre-existing material, which plausibly might have already previously undergone an evaporative event. Figure 11a shows small, but significant, differences in $\Delta^{25} \mathrm{Mg}$ between spinels and enclosing mantle melilite, whereas no difference is found for spinel and enclosing core melilite. Although small spinel-melilite differences are present, the closeness of the measured $\Delta^{25} \mathrm{Mg}$ for spinel and enclosing melilite is a possible problem for the relict spinel-perovskite model.

It is likely that the processes considered here occurred on time scales far less than the ${ }^{26} \mathrm{Al}$ radioactive decay lifetime, so measurable ${ }^{26} \mathrm{Al}$ age differences between relict spinel and host CAI are not expected.

The $\mathrm{Ti}^{+3}$-rich rims on $\mathrm{TS} 34$ spinels can be explained by late spinel crystallization or reequilibration under reducing conditions attained prior to, or during, clinopyroxene crystallization. In this scenario, the $\mathrm{Ti}^{+4}$-rich cores are due to perovskite, not oxidizing conditions. The environment surrounding the droplet is, however, highly reduced and interaction with the vapor ultimately leads to reduction of the $\mathrm{Ti}^{+4}$ in the liquid, so that any subsequent crystallization or reequilibration of spinel during cooling occurs in progressively more reduced liquids, leading to decreases in the $\mathrm{Ti}$ valence of spinel rims.

Beyond the above general features, several alternative scenarios are possible.

(A) Assuming that spinel is relict, it is possible that all of its properties were inherited from an earlier environment. This would have to be a $\mathrm{Ti}^{+4}$-rich source, perhaps spinel-perovskite CAIs (Kornacki and Wood 1985).

However, there are testable alternatives, involving Ti incorporation into spinel during the initial TS34 melting event:

(B) Perovskite is unstable in melts of bulk type B CAI composition, and virtually all $\mathrm{Ti}$ in perovskite is tetravalent. Thus, a simple variation is for perovskite dissolution to produce local $\mathrm{Ti}^{+4}$ enrichments. $\mathrm{Ti}^{+4}$ then partitions into an existing spinel, producing the observed high $\mathrm{Ti}^{+4}$ concentrations in the cores of the spinel grains. This assumes that temperature-time conditions are sufficient for the partitioning to occur.

(C) An alternative is to assume that only relict perovskite grains (i.e., no spinel) were present, which, as they dissolved, provided high- $\mathrm{Ti}^{+4}$ regions in the melt in which spinel crystals preferentially nucleated. This alternative would explain the similar $\mathrm{Mg}$ isotopic compositions of spinel and melilite in TS34. One difficulty with this idea is that $\mathrm{TiO}_{2}{ }^{*}$ maps of spinel crystals in mantle melilite do not show the splotchy distributions that might be expected from a growing spinel plowing through a region of scattered perovskite crystals that were dissolving or completely dissolved into the melt. Moreover, the assumption of preferential spinel nucleation is highly speculative. It seems more plausible to assume that both relict spinel and perovskite coexisted prior to melting and that the perovskite more or less evenly surrounded the early spinel crystal.

(D) $\mathrm{We}$ can also consider perovskite-spinel exchange models. If perovskite is in contact with spinel, the two phases can undergo $\mathrm{Al}-\mathrm{Ti}^{+4}$ exchange through the reaction

$$
\begin{aligned}
& \mathrm{CaTiO}_{3}(\mathrm{pv})+2 \mathrm{MgAl}_{2} \mathrm{O}_{4}(\mathrm{sp}) \\
& \quad=\mathrm{CaAlO}_{\frac{5}{2}}(\mathrm{pv})+\mathrm{Mg}_{2} \mathrm{TiO}_{4}(\mathrm{sp})+\frac{9}{8} \mathrm{Al}_{\frac{8}{3}} \mathrm{O}_{4}(\mathrm{sp}) .
\end{aligned}
$$

Here, $\mathrm{CaAlO}_{5 / 2}$ represents an aluminous perovskite component with an $\mathrm{O}$ vacancy, and $\mathrm{Al}_{8 / 3} \mathrm{O}_{4}$ represents an aluminous spinel component with excess oxygen. Note that this is a thermally activated equilibrium, 
independent of redox conditions and assumes that no reaction with ambient gas occurs, which could lead to $\mathrm{Ti}^{+4}$ reduction.

Under naturally occurring (e.g., nebular) conditions, little $\mathrm{Ti}$ is trivalent in perovskite. Under highly reducing conditions, the defect properties of nominally pure $\mathrm{X}^{+2} \mathrm{TiO}_{3}$ perovskites are dominated by reduction of $\mathrm{Ti}$ rather than defect equilibria controlled by small amounts of contaminants, but, even then, concentrations of $\mathrm{Ti}^{+3}$ are likely to be quite low (e.g., Chan and Smyth 1984; Zhou et al. 2002). Thus, reaction 6 is probably a governing reaction for $\mathrm{Ti}$ exchange between an isolated pair of adjacent perovskite and spinel grains over a broad range of redox conditions. Perovskites are commonly aluminous in CAIs that contain both spinel and perovskite (e.g., Kornacki and Wood 1985; Greshake et al. 1998; Simon et al. 1998), consistent with reaction 6. There appears to have been, however, no systematic study of the compositions of coexisting spinel and perovskite grains. The equilibrium constant for reaction 6 is unknown, but if it dominates Al-Ti exchange, it predicts that the number of cations of $\mathrm{Al}$ in the perovskite donor crystal(s) equals the number of cations of $\mathrm{Ti}^{+4}$ taken up by the spinel. This means that the amount of $\mathrm{Ti}$ in the spinel will be variable, reflecting the amount of perovskite in the vicinity. Ti will be dominantly tetravalent in any spinel equilibrated with perovskite by this mechanism.

It is important to note that spinels in two Allende FTAs have high Ti valence (Fig. 4c). Because type A CAIs contain perovskite, this would be consistent with reaction 6 controlling Ti contents and valence in the spinel because FTAs are thought not to have melted (MacPherson and Grossman 1984). One spinel, sp13, from A-WP1 has a much lower valence than the other grains, such that it falls on the line formed by the non-TS34 spinels in Fig. 4c. It is probably significant that this spinel is on the non-TS34 spinel line, but A-WP1 is a complex, heavily altered CAI (Paque et al. 2008) and more study of the petrographic context of this grain is required.

(E) Reactions between melilite and spinel involving Ti require oxygen for balance, but a comparable closedsystem reaction can be written for coexisting clinopyroxene and spinel:

$$
\begin{aligned}
\mathrm{CaTi}^{+3} \mathrm{AlSiO}_{6}(\mathrm{gr})+\mathrm{Mg}_{2} \mathrm{Ti}^{+4} \mathrm{O}_{4}(\mathrm{sp})+\mathrm{CaAl}_{2} \mathrm{SiO}_{6}(\mathrm{ku}) \\
=\mathrm{CaTi}^{+4} \mathrm{Al}_{2} \mathrm{O}_{6}(\mathrm{~T} 4 \mathrm{P})+\mathrm{MgAlTi}^{+3} \mathrm{O}_{4}(\mathrm{sp}) \\
\quad+\mathrm{CaMgSi}_{2} \mathrm{O}_{6}(\mathrm{di}) .
\end{aligned}
$$

where "gr," "ku," and "di" are grossmanite, kushiroite, and diopside pyroxene components, respectively. During the initial stages of crystallization, the available clinopyroxene would be the spinel boundary clinopyroxene, itself possibly formed by reaction of perovskite with melt. If reaction 7 dominated, the likely result would be considerable $\mathrm{Ti}^{+3}$ in the spinel, which is not observed in the cores of spinel grains from TS34. Depending on the equilibrium constant and activitycomposition relationships of the phases, reaction 7 may or may not increase the $\mathrm{TiO}^{*}$ concentration of spinel; however, it is possible that reaction 7 contributes to the observed trends toward lower valence for near-rim zoning and, in particular, it may be an important factor in why most spinel analyses from type B inclusions lie along a line on a plot of $\mathrm{Ti}$ valence versus $\mathrm{TiO}_{2}$ * (Fig. 4a). This is because smaller spinels that define the low Ti valence part of the trend in Fig. 4a can more easily equilibrate with boundary clinopyroxene, a source of $\mathrm{Ti}^{+3}$ to the spinel, than can the large spinels of TS34. It is also possible that the clinopyroxene in reaction 7 is mostly a proxy for melt.

\section{Constraints on Peak Temperature}

If heating during a melting event extended to a temperature above the liquidus for a long enough time, any relict spinel would have been dissolved and $\mathrm{TiO}_{2}$ * concentrations in the melt would have equilibrated throughout the molten droplet. However, assuming that the spinel cores in TS34 are relict and did not dissolve under initial melting conditions, we can place some constraints on peak temperature during the initial melting event. For example, in $\mathrm{B} 4$, the $\mathrm{Ti}^{+3}$-enriched rim is relatively well defined (e.g., Fig. 5), and the core comprises approximately $40 \%$ of the grain by volume (assuming that core and whole crystal form concentric right octahedra). If this is a typical core/rim ratio among spinels in TS34, then based on modes from the experiments of Stolper (1982), the core crystallizes at or above approximately $1470{ }^{\circ} \mathrm{C}$. This might underestimate the peak temperature because it would take some time at any temperature for the relict spinel crystals to dissolve sufficiently to achieve a modal abundance consistent with spinel saturation at that temperature (i.e., because the dissolution rate would be controlled by diffusion into the surrounding spinel undersaturated melt).

Under (time, temperature) conditions where $\mathrm{Ti}^{+4}$, initially in perovskite, is partitioned into spinel, it is possible that significant $\mathrm{Mg}$ isotopic exchange between spinel and liquid could occur, as $\mathrm{Mg}$ self-diffusion is faster than chemical diffusion of Ti. Modeling of these conditions is poorly constrained because of lack of knowledge of the initial $\Delta^{25} \mathrm{Mg}$ of the relict spinel. However, based on the Mg self-diffusion coefficients of Sheng et al. (1992), it is possible to estimate $7 \mathrm{~h}$ as the order of magnitude of the characteristic time scale, $\tau$, for equilibration of relict spinel with liquid at the $1470{ }^{\circ} \mathrm{C}$ peak temperature estimated above. We use: 
$\left\langle X^{2}>\approx 2 D \tau\right.$ where $X$ is a characteristic diffusion length and $D$ is the self-diffusion coefficient. The large spinel grains in TS34 in which $\Delta^{25} \mathrm{Mg}$ was measured are $60-80 \mu \mathrm{m}$ in size, so we adopt $35 \mu \mathrm{m}$ for $X$. The same effect (i.e., equivalent $D \tau$ ) as a $7 \mathrm{~h}$ soak at $1470{ }^{\circ} \mathrm{C}$ can be achieved by cooling from $1470{ }^{\circ} \mathrm{C}$ at approximately $9{ }^{\circ} \mathrm{C} \mathrm{h}^{-1}$ to $1150{ }^{\circ} \mathrm{C}$, the approximate appearance temperature for melilite (Fig. 13). This is also consistent with the postevaporative cooling rate of $10^{\circ} / \mathrm{h}$ inferred by Stolper and Paque (1986). There is considerable uncertainty in our calculation, but the equilibration of relict spinel with a liquid previously depleted in ${ }^{24} \mathrm{Mg}$ through evaporation is plausible.

\section{Low-Pressure Evaporation Model}

Calculations of the vapor phase composition in equilibrium with a CAI liquid at $1700 \mathrm{~K}$ (within the spinel-liquid field) as a function of total $\mathrm{H}_{2}$ pressure (Grossman et al. 2000) show that oxygen fugacity increases steadily with decreasing $\mathrm{H}_{2}$ pressure $\left(\mathrm{P}_{\mathrm{H}}\right)$ from IW-5 at $\mathrm{P}_{\mathrm{H} 2}=10^{-3}$ bar to IW-2 at $10^{-6}$ bar, reflecting important contributions of oxygen to the gas phase associated with vaporization of lithophile element oxides. For example, when $\mathrm{MgO}$ evaporates, it dissociates into $\mathrm{Mg}$ and $\mathrm{O}$, and $\mathrm{SiO}_{2}$ evaporates as $\mathrm{SiO}+\mathrm{O}$. At higher temperatures, therefore, conditions are more oxidizing at a given $\mathrm{H}_{2}$ pressure, e.g., IW-2.7 at $\mathrm{P}_{\mathrm{H} 2}=10^{-3}$ bar for $2000 \mathrm{~K}$. If a typical refractory condensate assemblage were heated, partially melted, and cooled into the spinel + liquid field under these conditions, the resulting spinel would have a high proportion of $\mathrm{Ti}^{+4}$ relative to $\mathrm{Ti}^{+3}$.

Spinel crystallized from a melt, which had undergone large amounts of evaporation, would also become enriched in heavy $\mathrm{Mg}$, acquiring positive $\Delta^{25} \mathrm{Mg}$, as observed. If all phases, including spinel, crystallized after evaporation from a ${ }^{25} \mathrm{Mg}$-enriched melt, the $\Delta^{25} \mathrm{Mg}$ of spinel and melilite should ideally be the same. If the spinel crystallized during evaporation, the $\Delta^{25} \mathrm{Mg}$ for spinel might have been less than that of melilite. Figure 11a shows small, but significant, excesses of $\Delta^{25} \mathrm{Mg}$ in spinel relative to host melilite for two of the three pairs analyzed. The origin of these differences, and the overall differences among the analyzed spinel, is unknown, but rapid evaporation has been shown experimentally to result in an isotopically inhomogeneous drop (Richter et al. 2006). The similarity in $\Delta^{25} \mathrm{Mg}$ of spinel and its host melilite is fairly naturally explained by low-pressure evaporation with spinel and melilite crystallizing from a melt of approximately constant $\Delta^{25} \mathrm{Mg}$.

High dust/gas ratios (relative to a system of solar composition) can also lead to higher oxygen fugacities (Ebel and Grossman 2000), but higher $\mathrm{Mg}$ and $\mathrm{SiO}$ fugacities in the ambient vapor surrounding a droplet also suppress volatilization and, consequently, mass fractionation of $\mathrm{Mg}$ in the residue. Evaporation of oxides from a partially molten droplet at low pressure and high temperature, with a rate that decreases with decreasing temperature and eventually ceases, provides a straightforward transition from high-temperature oxidizing conditions to more reducing conditions at lower temperatures; it does not account for observed differences in isotopic compositions of the constituent phases, as melilite would be expected to be heavier than spinel.

Clinopyroxene would crystallize when there was a much lower rate of evaporation-induced release of free oxygen, allowing re-establishment of normal, reducing nebular conditions, producing a $\mathrm{Ti}^{+3}$-rich liquid. The $\mathrm{Ti}^{+3}$-rich rims on spinels in TS34 could have crystallized/ re-equilibrated under these reducing conditions.

In Fig. 12, the spinel with the lowest valence (grain B2) is consistent with the expected bulk CAI liquid composition, and, therefore, with a low-pressure evaporation model. It is possible that the rims of other spinels are also consistent with this model, but we cannot determine the valence on that scale. The lowpressure evaporation model, however, does not account for the overall high $\mathrm{Ti}$ concentrations in spinel, which require bulk $\mathrm{TiO}_{2}{ }^{*}$ values that are much higher than observed (Fig. 12).

\section{Review and Evaluation of Models}

We emphasize that the models we chose for detailed evaluation may not be unique. For example, a model involving an altered (oxidized) precursor was mentioned above.

\section{Relict Spinel Plus Perovskite Models}

In addition to simply reflecting the previous environment (alternative A in the Relict SpinelPerovskite section), the spinel cores with high $\mathrm{Ti}$ valence can potentially be explained as a consequence of interactions between relict spinel-perovskite associations, either with themselves (alternative D) or with the melt (alternatives B, C). Finally, interaction between spinel and clinopyroxene (alternative $\mathrm{E}$ ) is possible.

Alternative B (local $\mathrm{Ti}^{+4}$ enrichment of the melt due to perovskite dissolution) is attractive because, accepting the presence of relict spinel-perovskite assemblages, the required events would almost certainly happen. During the melting event, perovskite is unstable because of the low bulk $\mathrm{Ti}$ content and it will, therefore, dissolve (unless armored by a host phase). The melt immediately surrounding a dissolving perovskite is Ti-rich and, specifically, $\mathrm{Ti}^{+4}$-enriched, because $\mathrm{Ti}$ in the dissolving phase is essentially all $\mathrm{Ti}^{+4}$. 
For the relict spinel-perovskite model, the closeness of $\Delta^{25} \mathrm{Mg}$ between spinel and coexisting melilite (Fig. 11a) must be ascribed to coincidence or to postevaporative $\mathrm{Mg}$ isotopic exchange between spinel and liquid, as discussed above.

No data are currently available on $\mathrm{V}$ valences in CAI perovskite; consequently, it is not possible to make predictions for $\mathrm{V}$ valences in spinels in the relict spinelperovskite model. Overall, the $\mathrm{V}$ valences shown in Fig. 10 are unexplained, but worthy of further study.

\section{Low-Pressure Evaporation Models}

Evaporation at low pressure is highly plausible and naturally produces sufficiently oxidizing conditions. Spinel and melilite both crystallize from the same evaporated melt and should have the same $\Delta^{25} \mathrm{Mg}$ if the melt was homogeneous. This is basically in accord with observations (Fig. 11a), the significant approximately $0.5 \%$ differences suggesting some isotopic heterogeneity in the melt. In contrast, it appears difficult to account for the high $\mathrm{Ti}^{+4}$ concentrations in spinel cores, provided the experimentally determined partition coefficients (Connolly and Burnett 2003) are correct.

\section{SUMMARY}

Our most important finding is that the cores of many spinel grains predominantly have low $\mathrm{Ti}^{+3} / \mathrm{Ti}^{+4}$ ratios, inconsistent with coexisting $\mathrm{Ti}^{+3}$-rich clinopyroxene. Constraints on models to account for the $\mathrm{Ti}^{+4}$-rich cores are (a) relatively high $\mathrm{Ti}$ concentrations in many spinels (Fig. 12), (b) the similarity of evaporation-derived ${ }^{25} \mathrm{Mg}$ enrichments between spinel and coexisting melilite (Fig. 11a), (c) the presence of $\mathrm{Ti}^{+3}$-rich rims on large spinels in TS34 (e.g., Fig. 5), and (d) trends in analyses cores of small grains for CAIs other than TS34 that show dramatic increase in $\mathrm{Ti}$ valence with increasing $\mathrm{TiO}_{2}{ }^{*}$ in spinel (Fig. 4a).

We have discussed two models: low-pressure evaporation, leading to crystallization of phases having isotopically heavy $\mathrm{Mg}$ in an oxidizing environment; and reactions involving relict spinel-perovskite assemblages, with spinel inheriting $\mathrm{Ti}^{+4}$ from perovskite. Both models require changes caused by transient conditions from those that form the $\mathrm{Ti}^{+4}$-rich cores to more "normal" reducing CAI conditions under which $\mathrm{Ti}^{+3}$ rich clinopyroxene crystallizes. Both models readily account for the $\mathrm{Ti}^{+3}$-rich rims as a consequence of the return to normal reducing conditions.

Acknowledgments-This work was supported by NASA grants NNX09AC35G (D. S. Burnett, PI); NNX09AG40G (E. Stolper, PI); NNX08AE06G (L.
Grossman, PI) and by a Monka-sho grant (H. Yurimoto, PI). We thank Jérôme Aléon and an anonymous reviewer for their constructive comments.

\section{Editorial Handling-Dr. Christine Floss}

\section{REFERENCES}

Amelin Y., Krot A. N., Hutcheon I. D., and Ulyanov A. A. 2002. Lead isotope ages of chondrules and calciumaluminum-rich inclusions. Science 297:1678-1683.

Badwal S. P. S., Bannister M. J., and Garrett W. G. 1987. Oxygen measurement with $\mathrm{SIRO}_{2}$ sensors. Journal of Physics E 20:531-540.

Beckett J. R. 1986. The origin of calcium-, aluminum-rich inclusions from carbonaceous chondrites: An experimental study. Ph.D. dissertation, University of Chicago, Chicago, Illinois, USA.

Beckett J. R., Spivack A. J., Hutcheon I. D., Wasserburg G. J., and Stolper E. M. 1990. Crystal chemical effects on the partitioning of trace elements between mineral and melt: An experimental study of melilite with applications to refractory inclusions from carbonaceous chondrites. Geochimica et Cosmochimica Acta 54:1755-1774.

Berman R. G. 1983. A thermodynamic model for multicomponent melts with application to the system $\mathrm{CaO}-\mathrm{MgO}-\mathrm{Al}_{2} \mathrm{O}_{3}-\mathrm{SiO}_{2}$. Ph.D. dissertation, University of British Columbia, Vancouver, British Columbia, Canada.

Catanzaro E. J., Murphy T. J., Garner E. L., and Shields W. R. 1966. Absolute isotopic abundance ratios and atomic weight of magnesium. Journal of Research of the National Bureau of Standards 70A:453-456.

Chan N.-H. and Smyth D. M. 1984. Defect chemistry of donor-doped $\mathrm{BaTiO}_{3}$. Journal of the American Ceramic Society 67:285-288.

Clayton R. N. 2005. Oxygen isotopes in meteorites. In Meteorites, comets, and planets, edited by Davis A. M. Treatise on Geochemistry, vol. 1. Amsterdam: Elsevier B. V. pp. 129-142.

Connolly H. C. Jr. and Burnett D. S. 2003. On type B CAI formation: Experimental constraints on $\mathrm{fO}_{2}$ variations in spinel minor element partitioning and reequilibration effects. Geochimica et Cosmochimica Acta 67:4429-4434.

Connolly H. C. Jr., Burnett D. S., and McKeegan K. D. 2003. The petrogenesis of type B1 Ca-Al-rich inclusions: The spinel perspective. Meteoritics \& Planetary Science 38:197-224.

Dowty E. and Clark J. R. 1973. Crystal structure refinement and optical properties of $\mathrm{a} \mathrm{Ti}^{+3}$ fassaite from the Allende meteorite. American Mineralogist 58:230-242.

Ebel D. S. 2006. Condensation of rocky material in astrophysical environments. In Meteorites and the early solar system II, edited by Lauretta D. S. and McSween H. Y. Jr. Tucson, Arizona: The University of Arizona Press. pp. 253-277.

Ebel D. S. and Grossman L. 2000. Melilite zoning during partial evaporation of calcium-aluminum-rich inclusion droplets. Meteoritics \& Planetary Science 35:A49.

Eng P. J., Newville M., Rivers M. L., and Sutton S. R. 1998. Dynamically figured Kirkpatrick-Baez micro-focusing optics. In X-ray microfocusing: Applications and technique, edited by McNulty I. Proc. SPIE 3449:145-156.

Farges F., Brown G. E. Jr., and Rehr J. J. 1997. Ti K-edge XANES studies of Ti coordination and disorder in oxide compounds: Comparison between theory and experiment. Physical Review B 56:1809-1819. 
Goswami J. N., Srinivasan G., and Ulyanov A. A. 1994. Ion microprobe studies of Efremovka CAIs: I. Magnesium isotope composition. Geochimica et Cosmochimica Acta 58:431-447.

Greshake A., Bischoff A., and Putnis A. 1998. Transmission electron microscope study of compact type A calciumaluminum-rich inclusions from CV3 chondrites: Clues to their origin. Meteoritics \& Planetary Science 33:75-87.

Grossman L. 1975. Petrography and mineral chemistry of Carich inclusions in the Allende meteorite. Geochimica et Cosmochimica Acta 39:433-454.

Grossman L., Ebel D. S., Simon S. B., Davis A. M., Richter F. M., and Parsad N. M. 2000. Major element chemical and isotopic compositions of refractory inclusions in $\mathrm{C} 3$ chondrites: The separate roles of condensation and evaporation. Geochimica et Cosmochimica Acta 64:2879-2894.

Grossman L., Ebel D. S., and Simon S. B. 2002. Formation of refractory inclusions by evaporation of condensate precursors. Geochimica et Cosmochimica Acta 66:145-161.

Grossman L., Beckett J. R., Fedkin A. V., Simon S. B., and Ciesla F. J. 2008a. Redox conditions in the solar nebula: Observational, experimental, and theoretical constraints. Reviews in Mineralogy \& Geochemistry 68:93-140.

Grossman L., Simon S. B., Rai V. K., Thiemens M. H., Hutcheon I. D., Williams R. W., Galy A., Ding T., Fedkin A. V., Clayton R. N., and Mayeda T. K. 2008b. Primordial compositions of refractory inclusions. Geochimica et Cosmochimica Acta 72:3001-3021.

Itoh S., Makide K., and Yurimoto H. 2008. Calculation of radiogenic ${ }^{26} \mathrm{Mg}$ of CAI minerals under high precision isotope measurement by SIMS. Applied Surface Science 255:1476-1478.

Johnston W. D. 1965. Oxidation-reduction equilibria in molten $\mathrm{Na}_{2} \mathrm{O} \cdot 2 \mathrm{SiO}_{2}$ glass. Journal of the American Ceramic Society 48:184-190.

Kennedy A. K., Beckett J. R., Edwards D. A., and Hutcheon I. D. 1997. Trace element disequilibria and magnesium isotope heterogeneity in 3655A: Evidence for a complex multi-stage evolution of a typical Allende Type B1 CAI. Geochimica et Cosmochimica Acta 61:1541-1561.

Kirkpatrick P. and Baez A. V. 1948. Formation of optical images by X-rays. Journal of the Optical Society of America 38:766-774.

Kornacki A. S. and Wood J. A. 1985. Mineral chemistry and origin of spinel-rich inclusions in the Allende CV3 chondrite. Geochimica et Cosmochimica Acta 49:1219-1237.

Krause M. O. and Oliver J. H. 1979. Natural widths of atomic $\mathrm{K}$ and $\mathrm{L}$ levels, $\mathrm{K}_{\alpha} \mathrm{X}$-ray lines and several KLL Auger lines. Journal of Physical and Chemical Reference Data 8:329-338.

Kuehner S. M., Davis A. M., and Grossman L. 1989. Identification of relict phases in a once-molten Allende inclusion. Geophysical Research Letters 16:775-778.

Lombard P., Boizet B., Ollier N., Jouin A., and Yoshikawa A. 2009. Spectroscopic studies of $\mathrm{Ti}^{3+}$ ions speciation inside $\mathrm{MgAl}_{2} \mathrm{O}_{4}$ spinels. Journal of Crystal Growth 311:899-903.

Ma C., Tschauner O., Beckett J. R., Rossman G. R., and Liu W. 2012. Panguite, $\left(\mathrm{Ti}^{4+}, \mathrm{Sc}, \mathrm{Al}, \mathrm{Mg}, \mathrm{Zr}, \mathrm{Ca}\right)_{1.8} \mathrm{O}_{3}$, a new ultra-refractory titania mineral from the Allende meteorite: Synchrotron micro-diffraction and EBSD. American Mineralogist 97:1219-1225.

MacPherson G. J. and Grossman L. 1984. "Fluffy" Type A $\mathrm{Ca}, \mathrm{Al}$-rich inclusions in the Allende meteorite. Geochimica et Cosmochimica Acta 48:29-46.
MacPherson G. J., Paque J. M., Stolper E., and Grossman L. 1984. The origin and significance of reverse zoning in melilite from Allende Type B inclusions. Journal of Geology 92:289-305.

McKeegan K. M. and Davis A. M. 2005. Early solar system chronology. In Meteorites, comets, and planets, edited by Davis A. M. Treatise on Geochemistry, vol. 1. Amsterdam: Elsevier B. V. pp. 431-460.

Mendybaev R. A., Beckett J. R., Stolper E., and Grossman L. 1998. Measurement of oxygen fugacities under reducing conditions: Non-Nernstian behavior of $\mathrm{Y}_{2} \mathrm{O}_{3}$-doped zirconia oxygen sensors. Geochimica et Cosmochimica Acta 62:3131-3139.

Paque J. M. and Stolper E. 1984. Crystallization experiments on a range of Ca-Al-rich inclusion compositions (abstract). 15th Lunar and Planetary Science Conference. p. 631.

Paque J. M., Burnett D. S., Beckett J. R., Hutcheon I. D., and Weber P. K. 2006. Origin of trace elements in spinel from Ca-Al-rich inclusions: Constraints from nanoSIMS analyses of spinel and enclosing melilite (abstract \#1823). 37th Lunar and Planetary Science Conference. CD-ROM.

Paque J. M., Burnett D. S., and Beckett J. R. 2007. Zoning patterns of $\mathrm{Fe}$ and $\mathrm{V}$ in spinel from a type $\mathrm{B}$ Ca-Al-rich inclusion: Constraints on subsolidus thermal history. Meteoritics \& Planetary Science 42:899-912.

Paque J. M., Beckett J. R., and Burnett D. S. 2008. Refractory metal nuggets as an indicator of alteration in a V-rich Ca-Al-rich inclusion (abstract \#1841). 39th Lunar and Planetary Science Conference. CD-ROM.

Paque J. M., Beckett J. R., Ishii H. A., Aléon-Toppani A., Burnett D. S., Teslich N., Dai Z. R., and Bradley J. P. 2009. The formation of boundary clinopyroxenes and associated glass veins in type B1 CAIs. Meteoritics \& Planetary Science 44:665-687.

Paque J. M., Sutton S. R., Burnett D. S., Beckett J. R., and Simon S. B. 2010. An intimate mix of highly oxidizing and highly reducing environments: Relict spinel determined by XANES in a partially melted Allende Ca-Al-rich inclusion (abstract \#1391). 41st Lunar and Planetary Science Conference. CD-ROM.

Pouchou J. L. and Pichoir F. 1984. A new model for quantitative X-ray microanalysis. Part I: Application to the analysis of homogeneous samples. La Recherche Aerospatiale 3:13-38.

Prewitt C. T., Shannon R. D., and White W. B. 1972. Synthesis of a pyroxene containing trivalent titanium. Contributions to Mineralogy and Petrology 35:77-82.

Richter F. M., Davis A. M., Ebel D. S., and Hashimoto A. 2002. Elemental and isotopic fractionation of Type B calcium-, aluminum-rich inclusions: Experiments, theoretical considerations, and constraints on their thermal evolution. Geochimica et Cosmochimica Acta 66:521-540.

Richter F. M., Mendybaev R. A., and Davis A. M. 2006. Conditions in the protoplanetary disk as seen by the type B CAIs. Meteoritics \& Planetary Science 41:83-93.

Richter F. M., Janney P. E., Mendybaev R. A., Davis A. M., and Wadhwa M. 2007. Elemental and isotopic fractionation of Type B CAI-like liquids by evaporation. Geochimica et Cosmochimica Acta 71:5544-5564.

Righter K., Sutton S. R., Newville M., Le L., Schwandt C. S., Uchida H., Lavina B., and Downs R. T. 2006. An experimental study of the oxidation state of vanadium in spinel and basaltic melt with implications for the origin of planetary basalt. American Mineralogist 91:1643-1656. 
Rubin A. E. 2012. A new model for the origin of type-B and fluffy type-A CAIs: Analogies to remelted compound chondrules. Meteoritics \& Planetary Science 47:1062-1074.

Sato M. 1971. Electrochemical measurements and control of oxygen fugacity and other gaseous fugacities with solid electrolyte sensors. In Research techniques for high pressure and high temperature, edited by Ulmer G. C. New York: Springer-Verlag. pp. 43-99.

Schreiber H. D. and Balazs G. B. 1982. Vanadium as an oxygen geobarometer in basaltic magmas: The further development of a geochemical electromotive force series in silicate melts (abstract). 13th Lunar and Planetary Science Conference. p. 692.

Schreiber H. D., Thanyasiri T., Lach J. J., and Legere R. A. 1978. Redox equilibria of $\mathrm{Ti}, \mathrm{Cr}$, and Eu in silicate melts: Reduction potentials and mutual interactions. Physics and Chemistry of Glasses 19:126-139.

Sheng Y. J., Wasserburg G. J., and Hutcheon I. D. 1992. Selfdiffusion of magnesium in spinel and in equilibrium melts-Constraints on flash heating of silicates. Geochimica et Cosmochimica Acta 56:2535-2546.

Simon S. B. and Grossman L. 2006. A comparative study of melilite and fassaite in Types B1 and B2 refractory inclusions. Geochimica et Cosmochimica Acta 70:780-798.

Simon S. B., Grossman L., and Davis A. M. 1991. Fassaite composition trends during crystallization of Allende Type B refractory inclusion melts. Geochimica et Cosmochimica Acta 55:2635-2655.

Simon S. B., Davis A. M., and Grossman L. 1998. Formation of an unusual compact type A refractory inclusion from Allende. Meteoritics \& Planetary Science 33:115-126.

Simon S. B., Davis A. M., and Grossman L. 1999. Origin of compact type A refractory inclusions from CV3 carbonaceous chondrites. Geochimica et Cosmochimica Acta 63:1233-1248.

Simon S. B., Sutton S. R., and Grossman L. 2007. Valence of titanium and vanadium in pyroxene in refractory inclusion interiors and rims. Geochimica et Cosmochimica Acta 71:3098-3118.

Simon S. B., Sutton S R., and Grossman L. 2010. Ti-XANES analyses of spinel in coarse-grained refractory inclusions from Allende. (abstract \#1459). 41st Lunar and Planetary Science Conference. CD-ROM.

Smith J. V. and Rivers M. L. 1995. Synchrotron X-ray microanalysis. In Microprobe techniques in the Earth sciences, edited by Potts P. J., Bowles J. F., Reed S. J., and Cave R. London: Chapman and Hall. pp. 163-233.

Stolper E. 1982. Crystallization sequences of Ca-Al-rich inclusions from Allende: An experimental study. Geochimica et Cosmochimica Acta 46:2159-2180.

Stolper E. and Paque J. M. 1986. Crystallization sequences of Ca-Al-rich inclusions from Allende: The effects of cooling rate and maximum temperature. Geochimica et Cosmochimica Acta 50:1785-1806.

\section{SUPPORTING INFORMATION}

Additional supporting information may be found in the online version of this article:

Appendix S1: Bulk compositions of experimental samples.
Sutton S. R. and Newville M. 2005. Vanadium K XANES of synthetic olivine: Valence determinations and crystal orientation effects (abstract \#2133). 36th Lunar and Planetary Science Conference. CD-ROM.

Sutton S. R. and Rivers M. L. 1999. Hard X-ray synchrotron microprobe techniques and applications. In Synchrotron methods in clay science, CMS Workshop Lectures 9, edited by Schulze D. G., Stucki J. W., and Bertsch P. M. Boulder, Colorado: The Clay Minerals Society. pp. 146163.

Sutton S. R., Bertsch P. M., Newville M., Rivers M., Lanzirotti A., and Eng P. 2002. Microfluorescence and microtomography analyses of heterogeneous earth and environmental materials. In Applications of Synchrotron Radiation in Low-Temperature Geochemistry and Environmental Science, edited by Paul A. Fenter, Mark L. Rivers, Neil C. Sturchio, and Stephen R. Sutton. Reviews in Mineralogy \& Geochemistry, vol. 49. pp. 429-483.

Sutton S. R., Karner J., Papike J., Delaney J. S., Shearer C., Newville M., Eng P., Rivers M., and Dyar M. D. 2005. Vanadium $\mathrm{K}$ edge XANES of synthetic and natural basaltic glasses and application to microscale oxygen barometry. Geochimica et Cosmochimica Acta 69:23332348.

Sylvester P. J., Simon S. B., and Grossman L. 1993. Refractory inclusions from the Leoville, Efremovka, and Vigarano $\mathrm{C} 3 \mathrm{~V}$ chondrites: Major element differences between types $\mathrm{A}$ and $\mathrm{B}$, and extraordinary refractory siderophile element compositions. Geochimica et Cosmochimica Acta 57:3763-3784.

Tranell G., Ostrovski O., and Jahanshahi S. 2002. The equilibrium partitioning of titanium between $\mathrm{Ti}^{3+}$ and $\mathrm{Ti}^{4+}$ valency states in $\mathrm{CaO}-\mathrm{SiO}_{2}-\mathrm{TiO}_{\mathrm{x}}$ slags. Metallurgical and Materials Transactions 33B:61-67.

Van Orman J. A. and Crispin K. L. 2010. Diffusion in oxides. Reviews in Mineralogy \& Geochemistry 72:757-825.

Wakaki S., Itoh S., Tanaka T., and Yurimoto H. 2013. Petrology, trace element abundances and oxygen isotopic compositions of a compound CAI-chondrule object from Allende. Geochimica et Cosmochimica Acta 102:261-279.

Wark D. A. 1979. Birth of the presolar nebula: The sequence of condensation revealed in the Allende meteorite. Astrophysics and Space Physics 65:275-295.

Waychunas G. A. 1987. Synchrotron radiation XANES spectroscopy of $\mathrm{Ti}$ in minerals: Effects of $\mathrm{Ti}$ bonding distances, Ti valence and site geometry on absorption edge structure. American Mineralogist 72:89-101.

Yoneda S. and Grossman L. 1995. Condensation of CaO$\mathrm{MgO}-\mathrm{Al}_{2} \mathrm{O}_{3}-\mathrm{SiO}_{2}$ liquids from cosmic gases. Geochimica et Cosmochimica Acta 59:3413-3444.

Zhou M. F., Bak T., Nowotny J., Rekas M., Sorrell C. C., and Vance E. R. 2002. Defect chemistry and semiconducting properties of calcium titanate. Journal of Materials Science 13:697-704.

Appendix S2: Ti valence profiles for TS34 spinel inclusions in anorthite.

Appendix S3: Theoretical modeling of $\mathrm{Ti}$ and $\mathrm{Ca}$ intensity profiles.

Appendix S4: Aluminum, magnesium, and oxygen isotopic results. 